\title{
Impact of Stochastic Entrainment in the NCAR CAM Deep Convection Parameterization on the Simulation of South Asian Summer Monsoon
}

RAJU PATHAK ( $\nabla$ rajuphyamu@gmail.com )

Indian Institute of Technology Delhi https://orcid.org/0000-0002-2734-4300

Sandeep Sahany

Indian Institute of Technology Delhi

Saroj Kanta Mishra

Indian Institute of Technology Delhi

\section{Research Article}

Keywords: Stochastic Entrainment, South Asian, Parameterization

Posted Date: May 4th, 2021

DOI: https://doi.org/10.21203/rs.3.rs-473790/v1

License: (c) (i) This work is licensed under a Creative Commons Attribution 4.0 International License.

Read Full License 
1 Impact of Stochastic Entrainment in the NCAR CAM Deep Convection Parameterization on the Simulation of South Asian Summer Monsoon 


\section{Abstract}

23 Model simulations are highly sensitive to the formulation of the atmospheric mixing process or

24 entrainment in the deep convective parameterizations used in their atmospheric component. In this

25 paper, we have implemented stochastic entrainment in the deep convection scheme of NCAR

26 CAM5 and analyzed the improvements in model simulation, focusing on the South Asian Summer

27 Monsoon (SASM), as compared to the deterministic entrainment formulation in the default version

28 of the model. Simulations using stochastic entrainment (StochCAM5) outperformed default model

29 simulations (DefCAM5), as inferred from multiple metrics associated with the SASM.

30 StochCAM5 significantly alleviated some of the longstanding SASM biases seen in DefCAM5,

31 such as precipitation pattern and magnitude over the Arabian Sea and western Equatorial Indian

32 ocean, early monsoon withdrawal, and the overestimation (underestimation) in the frequency of

33 light (large-to-extreme) precipitation. Related SASM dynamical and thermodynamical features,

34 such as Somali Jet, low-level westerly winds, and meridional tropospheric temperature gradient

35 (MTTG), are improved in StochCAM5. Further, the simulation of monsoon intra-seasonal

36 oscillation (MISO), Madden Julian Oscillation (MJO), and equatorial Kelvin waves are improved

37 in StochCAM5. Many essential climate variables, such as shortwave and longwave cloud forcing,

38 cloud cover, relative and specific humidity, and precipitable water, show significant improvement 39 in StochCAM5. 


\section{Introduction}

The conventional global climate models (GCMs) have failed to adequately parameterize

42 sub-grid scale cloud and convection processes that occur either in a small region or dissipate

43 instantly (e.g., Jones and Randall 2011). Most current GCMs use a convection parameterization

44 scheme that describes the ensemble mean effects of sub-grid scale convection and cloud processes

45 at the resolved grid-scale while ignoring individual cloud variability (e.g., Palmer 2001; Lin and

46 Neelin 2003; Langan et al. 2014). Previous research has shown that this missing variability is

47 important for realistic simulation of tropical climate systems (e.g., Moncrieff et al. 2012; Waliser

48 et al. 2012) and has used two distinct approaches to incorporate this heterogeneity in GCMs: super-

49 parameterization and stochastic parameterization. For super-parameterization, a cloud-resolving

50 model (CRM) that explicitly resolves sub-grid scale convective processes is used in each GCM

51 grid (e.g., Grabowski and Smolarkiewicz 1999; Khairoutdinov and Randall 2001; Krishnamurthy

52 et al. 2014). On the other hand, for stochastic parameterization, a stochastic term is used in a

53 conventional parameterization scheme (e.g., Buizza et al. 1999; Bright and Mullen 2002; Lin and

54 Neelin 2003; Shutts 2005; Khouider and Majda 2006; Plant and Craig 2008; Khouider et al. 2010;

55 Dorrestijn et al. 2013; Deng et al. 2015). Jones et al. (2019a) developed a different variant of super-

56 parameterization by incorporating multiple CRMs in each GCM grid and initializing each CRM

57 with a unique set of random thermal perturbations (referred to as multiple-instance super58 parameterization).

Compared to conventional convective parameterization, super-parameterization has made

60 significant advances in weather and climate prediction, especially over the tropics. For example,

61 super parameterization has significantly improved the simulations of Madden Julian Oscillation

62 (MJO; Madden and Julian 1971), tropical precipitation, El-Niño southern oscillation, and tropical 
63 cyclones (e.g., Khairoutdinov and Randall 2001; Benedict and Randall 2009, 2011; Stan et al.

64 2010; DeMott et al. 2011, 2013; Pritchard et al. 2011; Arnold et al. 2013; Krishnamurthy et al.

65 2014; Pritchard et al. 2014). Goswami et al. (2015) used super-parameterization in the CFSv2

66 model and reported an improved simulation of intra-seasonal oscillation (ISO) during the South

67 Asian summer monsoon (SASM). However, super-parameterization simulations are

68 computationally expensive, so their use is limited. On the other hand, stochastic parameterization

69 simulations consume computational resources similar to conventional GCMs and outperform

70 them. For example, Goswami et al. (2017a) used the stochastic multi-cloud model scheme (MCM;

71 Khouider et al. 2010; Dorrestijn et al. 2013; Deng et al. 2015) in CFSv2 and reported an improved

72 simulation of tropical synoptic and intra-seasonal variability. Several other researchers also

73 incorporated a stochastic noise term into the grid-scale mean-field and noted an enhanced

74 simulation of tropical diurnal variability and equatorial waves (e.g., Buizza et al. 1999; Bright and

75 Mullen 2002; Lin and Neelin 2003; Shutts 2005; Berner et al. 2009). Wang et al. (2016a, b; 2017)

76 used the stochastic approach of Plant and Craig 2008 in CAM5 to compute the properties of a

77 plume of a given mass stochastically using the Poisson distribution, and they found an improved

78 simulation of precipitation extremes and variability over the tropics.

79 While the above advances in climate modeling, precipitation biases over South Asia,

80 equatorial Indian ocean (EIO), inter-tropical convergence zone (ITCZ), and South Pacific

81 convergence zone (SPCZ) worsen (e.g., Wang et al. 2016a, 2017; Goswami et al. 2017a).

82 Furthermore, simulations of precipitation extremes and inter-annual variability over the Indian

83 subcontinent, quasi-biweekly oscillation (10-20 days), and MISO (30-60 days) need to be

84 improved (e.g., Goswami et al. 2017a,b; Wang et al. 2018). Jones et al. (2019b) also found that 
85 using the multiple-instance super-parameterization in GCMs did not improve the simulation of $86 \quad$ MJO and equatorial waves.

88 scale cloud and convection processes with large-scale circulations can improve the ISO simulation

89 (e.g., Jiang et al. 2011; DeMott et al. 2011; Abhik et al. 2013). Wang et al. (2018) used the Plant

90 and Craig (2008) scheme in CAM5 to link the stochastic generation of convective clouds to large-

91 scale vertical velocity and reported an improvement in Indian summer monsoon (ISM) simulation

92 but a deterioration in precipitation simulation over the equatorial region. Siebesma et al. (2003)

93 shown that the variation in lateral entrainment rate (i.e., the interaction between the updrafts and

94 the environment) is critical for accounting variability between different updrafts and allowing

95 updrafts to terminate at different levels. It has been found to be sensitive to precipitation extremes,

96 cyclone intensity, climate variability, cloud feedbacks, and climate sensitivity (e.g., Held et al.

97 2007; Knight et al. 2007; Bechtold et al. 2008; Joshi et al. 2010; Yang et al. 2013; Sherwood et al.

98 2014; Qian et al. 2015; Kooperman et al. 2018). For example, Bush et al. (2014) shown that SASM

99 precipitation biases are highly sensitive to entrainment rate using the MetUM model. Oueslati and

100 Bellon (2013) shown that double ITCZ in the Pacific ocean is sensitive to the entrainment rate of

101 convective plumes in the CNRM-CM5 model and that increasing the entrainment rate resulted in

102 a significant reduction in double ITCZ and SPCZ related biases.

In general, several attempts have been made to improve entrainment formulations in GCMs

104 (e.g., Neggers et al. 2002; Siebesma et al. 2003; Rio et al. 2010), but most of them do not allow

105 for large variability of entrainment among different updrafts. For example, in Neggers et al. (2002),

106 the entrainment rate is assumed to be the inverse product of updraft vertical velocity and a constant

107 entrainment time-scale. This approach, however, is highly sensitive to the entrainment time-scale 
108 specification, and all moist updrafts entrain the environmental air, resulting in a decrease in

109 buoyancy and thereby restricting the updrafts from reaching to neutral buoyancy level (Romps and

110 Kuang 2010). Raymond and Blyth (1986) proposed a different view of entrainment rate

111 formulation that the variability in cloud updrafts can be represented by a stochastic entrainment

112 rate, which has been investigated for shallow convective and non-precipitating convective

113 boundary layer clouds using LES and single-column model (SCM) runs (e.g., Romps and Kuang

114 2010; Nie and Kuang 2012, Sušelj et al. 2013, 2014). Sušelj et al. (2013) used stochastic

115 entrainment in an SCM above the condensation level (LCL) by assuming lateral entrainment as a

116 discrete (rather than a continuous) process and a well-mixed environmental air in the dry updraft

117 region (i.e., below LCL). As a result, the entrainment rate value in the dry updraft region is not

118 sensitive to model results (could be seen in Sušelj et al. 2012) and is set to a constant value for

119 simplicity. This implementation has improved the representation of convective boundary layer

120 clouds in SCM through an improved simulation of turbulent fluxes. In addition to these stochastic

121 entrainment-based LES and SCM runs, the implementation and evaluation of stochastic

122 entrainment rate in a GCM must be thoroughly studied for realistic simulation of global and

123 regional climate.

124 In this study, we implement a stochastic entrainment rate in CAM5's deep convection

125 scheme. In the deep convection scheme, the dilute convective available potential energy (CAPE)

126 is calculated by assuming continuous atmospheric mixing at a constant entrainment rate (Neale et

127 al. 2008). This dilute CAPE is further used in the closure assumption to estimate cloud-base updraft

128 mass-flux and trigger mechanisms (Zhang and McFarlane 1995). As a consequence, implementing

129 a stochastic entrainment rate in CAM5 would also result in stochasticity in closure and trigger

130 mechanism. This study focuses on the impact of stochastic entrainment on SASM simulations as 
131 part of an effort to improve SASM and India's climate simulations by the Department of Science

132 and Technology's Centre of Excellence in Climate Modeling at the Indian Institute of Technology

133 Delhi (Dash et al. 2017). The manuscript is organized as follows: Section 1 presents an

134 introduction, Section 2 describes the model details, implementation approach, model simulations

135 and observational data, and Section 3 presents results and discussion. Particularly, in Section 3,

136 we discuss precipitation pattern in Section 3.1, moisture distribution in Section 3.2, cloud

137 properties in Section 3.3, low-level and upper-level wind distribution in Section 3.4, north-south

138 wavenumber frequency spectrum in Section 3.5, and east-west wavenumber frequency spectrum

139 in Section 3.6. Finally, Section 4 concludes the study.

141 2. Model Details, Implementation Approach, Simulations, and Observational Data

$142 \quad 2.1 \quad$ Model Details

143 For simulations, the NCAR Community Atmosphere Model version-5.3 (CAM5) is used

144 within the framework of Community Earth System Model version-1.2.2. In CAM5, the finite

145 volume dynamical core, moist turbulence scheme, and shallow convection scheme are used from

146 Lin (2004), Bretherton and Park (2009), and Park and Bretherton (2009, respectively. The revised

147 Zhang-McFarlane (1995) scheme by Neale et al. (2008) to account for the dilute CAPE

148 computation and by Richter and Rasch (2008) to account for the convective momentum transport

149 is used for the treatment of deep convection (hereafter, ZMNR). The stratiform microphysical

150 scheme from Morrison and Gettelman (2008), the ice crystal nucleation from Liu et al. (2007), and

151 the ice supersaturation from Gettelman et al. (2010) are used. The Rapid Radiative Transfer Model

152 (RRTM) is used to calculate the radiative fluxes (Iacono et al. 2008; Mlawer et al. 1997). 


\subsection{Implementation Approach}

In CAM5, the ZMNR scheme is modified to account for the stochastic and discrete nature

156 of the entrainment process, as compared to the prescribed constant entrainment rate across vertical

157 levels. The stochastic entrainment approach used in this paper closely follows the approach used

158 by Sušelj et al. (2013) for convective boundary layer clouds in SCM. We also use Romps and

159 Kuang's (2010) findings that the model results are unaffected by changes in entrainment values

160 below LCL (i.e., in dry updrafts that have a well-mixed environmental air). As a result, the

161 entrainment rate $(\varepsilon)$ below LCL is set to a constant value of $0.1 \times 10^{-3} \mathrm{~m}^{-1}$, which is the entrainment

162 rate used in CAM5 (Neale et al. 2008), and the stochastic entrainment rate above the LCL is

163 implemented in the manner described by Sušelj et al. (2013).

164 For a small distance $d z$ ascends of updrafts above LCL, the probability of an entrainment 165 event is determined by a random number $(\beta)$ drawn from the Bernoulli distribution with a value

166 of zero (representing no entrainment event) or one (representing an entrainment event) with a 167 probability equal to $d z / L_{0}$, where $L_{0}$ represents the average distance that the updrafts must 168 traverse to entrain once (or the average distance between two entrainment events). Sušelj et al. 169 (2013) assumed that the fractional entrained mass flux at each entrainment event is proportional 170 to the vertical mass flux of updrafts and equal to $\varepsilon_{d} M_{u}$. These assumptions are used to parameterize 171 entrainment rate, as shown in Eq. 1.

$$
\varepsilon=s \varepsilon_{d} B\left(\frac{d z}{L_{0}}\right)
$$

173 Further, for a finite distance $\Delta z$ ascends of updrafts, the number of entrainment events is

174 determined by a random number $(\varphi)$ drawn from the Poisson distribution with a probability equal 175 to $\Delta z / L_{0}$, and the profile of entrainment rate is parameterized as shown in Eq. 2.

$$
\varepsilon(\Delta z)=\frac{1}{\Delta z} \varepsilon_{d} \varphi\left(\frac{\Delta z}{L_{0}}\right)
$$


177 where, $\frac{1}{\Delta z}$ is the shape parameter since the entrainment profile varies more steeply with height.

178 Based on sensitivity studies for $\varepsilon_{d}$ and $L_{0}$ conducted over the SASM and global region, as

179 well as previous studies (Sušelj et al. 2013; Romps and Kuang 2010), the value of $L_{0}$ and $\varepsilon_{d}$ are

180 prescribed to $\varepsilon_{d}=0.2$ and $L_{0}=100 \mathrm{~m}$ (i.e., each event leads to entrainment of $\sim 20 \%$ of the vertical

181 mass flux over an average distance of $L_{0}=100 \mathrm{~m}$ ). For simplicity, the distance $\Delta z$ is considered

182 here as the difference between two vertical model levels. The complete structure of the stochastic

183 entrainment is shown in Figure 1. From the sensitivity studies (see Supp. Figure S1), changing $\varepsilon_{d}$

184 and $L_{0}$ from their original value at the same time has no significant effect on the model results. For

185 example, changing $\varepsilon_{d}$ and $L_{0}$ values together from (i) $\varepsilon_{d}=0.1$ and $L_{0}=300$ to $\varepsilon_{d}=0.2$ and $L_{0}=$

186600 , and (ii) $\varepsilon_{d}=0.1$ and $L_{0}=500$ to $\varepsilon_{d}=0.2$ and $L_{0}=1000$ results in no significant change in the

187 vertical velocity and humidity over the tropical region. On the other hand, the simulation

188 performed by fixing any one of these parameters $\left(\varepsilon_{d}\right.$ or $\left.L_{0}\right)$ at a time and varying the other

189 parameter shows changes in vertical velocity and humidity distribution. As a result, we anticipate

190 that the model results would be generally sensitive to a single parameter (i.e., either $\varepsilon_{d}$ or $L_{0}$ )

191 affecting the entrainment rate.

192

$193 \quad 2.3 \quad$ Simulations and Observational Data

194 We performed two CAM5 simulations, one with the default ZMNR (DefCAM5) and the other 195 with the stochastic ZMNR (StochCAM5). Each simulation is run for 13-years at a horizontal 196 resolution of $0.9^{\circ}$ latitude and $1.25^{\circ}$ longitude, and 30 vertical levels, with the prescribed 197 climatological monthly sea surface temperature. The first year of simulation is used as a spin-up 198 period, and the remaining 12-years data are used for analysis. 
The following observations and reanalysis data are used in this study for model evaluation:

200 the Global Precipitation Climatology Project (GPCP; Adler et al. 2003) for monthly total

201 precipitation, the Tropical Rainfall Measuring Mission (TRMM) 3A12 for monthly convective

202 and large-scale precipitation (Kummerow et al. 1998) and 3B42 for daily total precipitation

203 (Huffman et al. 2007). The monthly convective precipitation for GPCP is computed using the total

204 to convective precipitation ratio from TRMM 3A12 (see Pathak et al. 2019 for the methodology

205 used for calculation), and the corresponding large-scale precipitation is obtained by taking out the

206 convective component from total precipitation. In addition, we also use the Clouds and Earth's

207 Radiant Energy System-Energy Balanced and Filled (CERES-EBAF; Loeb et al. 2009) project for

208 shortwave cloud forcing (SWCF) and longwave cloud forcing (LWCF), the National Aeronautics

209 and Space Administration (NASA) Water Vapor Project (NVAP; Randel et al. 1996) for

210 precipitable water and liquid water path, and the high-resolution data series of International

211 Satellite Cloud Climatology Project (ISCCP; Young et al. 2018) for low, middle, high, and total

212 cloud fraction. The horizontal and vertical wind, air temperature, relative humidity, and specific

213 humidity are obtained from the ECMWF reanalysis (ERA-I; Dee et al. 2011). These observed or

214 reanalysis datasets are first linearly interpolated to model resolution, and the climatological mean

215 of these datasets is used for this study.

216

$217 \quad$ 3. Results and Discussion

218 The DefCAM5 and StochCAM5 simulations are evaluated using the Taylor diagram over 219 the tropics (Figure 2) and Table 1 over the SASM region. Overall, StochCAM5 outperforms 220 DefCAM5 in simulating the oceanic rainfall, shortwave cloud forcing (SWCF), longwave cloud 221 forcing (LWCF), zonal wind at $850 \mathrm{hPa}$, and vertical wind at $500 \mathrm{hPa}$ over the tropical and SASM 
222 region. The frequency distribution of percentage bias for annual mean precipitation (Figure 3)

223 shows that the frequency of large percentage bias (greater than 60\%) does not differ much between

224 StochCAM5 and DefCAM5, except for a decrease (increase) in the frequency of moderate

225 percentage bias (30-60\%) over tropical land (ocean) in StochCAM5. For the seasonal mean (June-

226 August) precipitation, the frequency of moderate percentage bias (30-60\%) and small percentage

227 bias (less than 30\%) is greatly reduced over the tropical land but greatly increased the frequency

228 of small percentage bias over the tropical ocean. In general, the large increase in the frequency of

229 small percentage bias over the tropical ocean leads to a significant improvement in precipitation

230 during the SASM period.

\section{$232 \quad 3.1 \quad$ Precipitation Pattern}

233 Figure 4 shows the spatial distribution of JJAS mean total, convective, and large-scale

234 precipitation from observations and simulations, as well as their differences. The simulated total

235 precipitation pattern from DefCAM5 and StochCAM5 is found to be comparable to observations,

236 with average values of $4.06,4.96$, and $5.01 \mathrm{~mm} /$ day over the tropical region for observations,

237 DefCAM5, and StochCAM5, respectively. The large overestimation over the Arabian Sea (AS),

238 western Indian ocean, and underestimation over the north-east Bay of Bengal (BoB), northeast

239 India, and Indo-Burmese mountains in DefCAM5 are significantly alleviated in StochCAM5, but

240 the overestimation over the leeward side of the Western Ghats (WG) is significantly deteriorated.

241 StochCAM5 also shows a decrease in total precipitation overestimation over SPCZ and ITCZ in

242 the Pacific ocean. These improvements in total precipitation simulation from StochCAM5 are

243 found due to an improved partitioning between convective and large-scale precipitation. For

244 example, StochCAM5 reduces the convective precipitation overestimation and large-scale 
245 precipitation underestimation over the majority of South Asia. With StochCAM5, an increase in 246 pattern correlation (PCC) and a decrease in root mean square error (RMSE) are also found for total 247 precipitation (PCC: 0.68; RMSE: $2.96 \mathrm{~mm} /$ day), convective precipitation (PCC: 0.74; RMSE: 2.48 $248 \mathrm{~mm} /$ day) and large-scale precipitation (PCC: 0.42; RMSE: $2.04 \mathrm{~mm} /$ day) as compared to 249 DefCAM5 for total precipitation (PCC: 0.63; RMSD: $3.03 \mathrm{~mm} /$ day), convective precipitation 250 (PCC: 0.67; RMSE: $2.81 \mathrm{~mm} /$ day) and large-scale precipitation (PCC: 0.34; RMSE: $2.16 \mathrm{~mm} /$ day) 251 (Figure 4). This is advantageous to the model because the total precipitation biases over South 252 Asia have been a longstanding problem in CAM5 and its predecessors (e.g., Wang et al. 2016a; 253 Anand et al. 2018; Mishra et al. 2018), as well as in CMIP5 (e.g., Sperber et al. 2013). It was not 254 greatly alleviated, even after including stochasticity in the generation of convective clouds (Wang 255 et al. 2016a) and linking it to large-scale vertical velocity (Wang et al. 2018). Further breaking 256 convective precipitation into contributions from the deep and shallow convections (Supp. Figure 257 S2), we find a significant decrease (increase) in deep (shallow) convection over South Asia, except 258 the WG, northeast India, and Indo-Burmese mountains, which show an increase in deep convection 259 in StochCAM5 as compared to DefCAM5. As a result, the improvement in total precipitation 260 simulation over the AS and western Indian ocean from StochCAM5 is due to a decrease in 261 convective precipitation from deep convection, while the worsening over the leeward side of WG 262 is due to an increase in convective precipitation from both deep and shallow convections.

263 In regard to the annual cycle of total precipitation over the Indian land, both DefCAM5 264 and StochCAM5 simulate an earlier monsoon onset (in May), earlier peak precipitation (in mid265 June to early-July), and a larger peak precipitation magnitude with respect to observations (Figure 266 5a). However, as compared to DefCAM5, the monsoon withdrawal date ( 10 days earlier in 267 DefCAM5) is improved in StochCAM5, but the monsoon onset date ( 10 days earlier in 
DefCAM5) is simulated similar to DefCAM5 with no discernible change (see section 3.4 and

269 Figure 13 for more details), and the peak precipitation magnitude is worsened (approximately $25 \%$

270 greater) in StochCAM5 than DefCAM5 (Figure 5a). The overall deterioration of the annual cycle

271 of total precipitation is largely coming from the Western Ghats due to a large increase in both deep

272 convective precipitation and large-scale precipitation. We speculate that this increase is associated

273 with the corresponding increase in moisture flux convergence (Supp. Figure S3), which is followed

274 by higher deep convection and latent heat release and a positive feedback cycle leading to further

275 convergence and a further increase in total precipitation.

276 Further, the frequency distribution of precipitation rate (Figure 5b) shows that the

277 frequency of light precipitation rate (1-10 mm/day) and moderate precipitation rate (10-20

$278 \mathrm{~mm} /$ day) in DefCAM5 is overestimated, while the frequency of very heavy (extreme) precipitation

279 rate (greater than $40 \mathrm{~mm} /$ day) is underestimated (also seen in CMIP5 models by Jain et al. 2019

280 and Salunke et al. 2019). StochCAM5 improves the frequency distribution of precipitation rate, as

281 well as the contributions of light to extreme precipitation rates to total precipitation (Figure 5c).

282 The improved frequency distribution in StochCAM5 could be to the improved sub-grid scale

283 process representation by launching convective clouds with stochastically varying entrainment

284 rates. The improvement in the frequency distribution of precipitation has also been noted by 285 linking the stochastic Plant and Craig (2008) scheme to large-scale vertical velocity (Wang et al. 286 2018).

\section{$288 \quad 3.2 \quad$ Moisture Distribution}

289 Figure 6 shows the JJAS mean vertical cross-section of specific humidity and relative 290 humidity from ERA-I and model simulations, as well as their differences, over $0^{\circ}-30^{\circ} \mathrm{N}$. 
291 DefCAM5 shows a positive bias over $40^{\circ}-70^{\circ} \mathrm{E}$ and a negative bias over $70^{\circ}-140^{\circ} \mathrm{E}$ in the entire

292 troposphere for specific humidity. StochCAM5 alleviates the positive and negative biases seen in

293 DefCAM5 for specific humidity, resulting in a better simulation of specific humidity over the

294 above regions (Figure 6a-c). For relative humidity, StochCAM5 shows a decrease in positive bias

295 over $40^{\circ}-65^{\circ} \mathrm{E}$ and a negative bias over $90^{\circ}-120^{\circ} \mathrm{E}$ seen in DefCAM5. However, StochCAM5 also

296 shows a deterioration in positive bias over $120^{\circ}-140^{\circ} \mathrm{E}$ below $800 \mathrm{hPa}$ for relative humidity (Figure 297 6d-f).

298 Figure 7 shows the JJAS mean total column water vapor (CWV) from NVAP observations

299 and simulations, as well as their differences. DefCAM5 and StochCAM5 both underestimate the

$300 \mathrm{CWV}$ over the Indian land, BoB, central and eastern parts of the EIO, and western Pacific ocean,

301 while overestimating the CWV over the Arabian Peninsula, Tibetan region, western AS, and

302 southern Indian ocean. When compared to DefCAM5, StochCAM5 decreases CWV biases over

303 the western AS, southern Indian ocean, and western Pacific ocean while slightly increasing the

304 CWV biases over the Indian land. Overall, the average CWV value over South Asia has been

305 reduced from $42.03 \mathrm{~mm}$ in DefCAM5 to $41.99 \mathrm{~mm}$ in StochCAM5, resulting in better agreement

306 with $41.84 \mathrm{~mm}$ in NVAP observation. In addition, the RMSE of CWV over South Asia has been

307 decreased from $4.9 \mathrm{~mm}$ in DefCAM5 to $4.74 \mathrm{~mm}$ in StochaCAM5. These CWV improvements

308 are caused by a better distribution of specific humidity from 800 to 200 over western AS and the

309 southern Indian ocean and surface to $600 \mathrm{hPa}$ over BoB and the western Pacific ocean (Figure not

310 shown).

311

312

313 


\section{$314 \quad 3.3 \quad$ Cloud Properties}

315 To understand the factors that influence precipitation and water vapor, we analyze the 316 changes in cloud properties induced by stochastic entrainment. Since the cloud microphysical

317 processes associated with cloud liquid water and ice are used in CAM5 to calculate large-scale 318 precipitation from stratiform clouds (Morrison and Gettelman 2008), in Figure 8, we show the 319 JJAS mean cloud liquid water path (LWP) over South Asia from NVAP observations and 320 simulations, as well as their differences, and in Figure 9, we show the ice water path (IWP) 321 difference between StochCAM5 and DefCAM5. Figure 8 shows that DefCAM5 highly 322 underestimates LWP over northern BoB, eastern EIO, and western Pacific ocean. StochCAM5, on 323 the other hand, alleviates DefCAM5's LWP underestimation over northern BoB, AS, and western

324 Pacific ocean, making it closer to NVAP observations. In addition to the above improvements in 325 LWP, StochCAM5 also shows a deterioration in LWP over the western Indian ocean. Figure 10 326 shows that in StochCAM5, there is a decrease in IWP over the majority of South Asia, with a 327 significant decrease over the western Indian ocean and an increase over WG and northeast India. 328 Overall, the regions of increased LWP and IWP correspond well to regions of increased large329 scale precipitation (Figure 41).

330 Further, we show the difference in detrained liquid water (DLW) and detrained ice water 331 (DICE) over South Asia in Figure 10a, since the DLW and DICE from deep and shallow 332 convection relate to LWP and IWP in large-scale stratiform clouds and convective clouds (e.g., 333 Morrison and Gettelman 2008; Wang et al. 2016a). We find that StochCAM5 has increased DLW 334 from shallow convection. As this increased DLW is fed into the cloud microphysical 335 parameterization as a source for large-scale cloud ice and water, it increases LWP and IWP 336 (Morrison and Gettelman 2008), and thus the large-scale precipitation. Besides that, StochCAM5 
337 has increased the convective mass flux for shallow convection (and thus the increased DLW) and 338 decreased it for deep convection (Figure 10b), resulting in increased shallow convective clouds 339 and decreased deep convective clouds (Figure 10c). These changes in clouds are also reflected in 340 the increased precipitation from shallow convection and the decreased precipitation from deep 341 convection in StochCAM5 (Supp. Figure S2). From Supp. Figure S4, we find that StochCAM5

342 decreases the frequency of occurrence of deep convection while increasing the frequency of 343 occurrence of shallow convection over the tropical and southern subtropical regions. We speculate 344 this could be due to the increased entrainment rate, which results in low buoyancy (as seen from 345 CAPE; Supp. Figure S4) and thus decreased deep convection and moisture in the middle to high 346 levels. Zhang and Mu (2005) also showed that the reduced deep convection favors the build-up of 347 CAPE, which could lead to an increase in the frequency of occurrence of shallow convection. 348 Furthermore, the large decrease in ice clouds in the upper troposphere in StochCAM5 is found to 349 decrease the total cloud ice amount, and possibly it could be one of the reasons for a large decrease 350 in IWP over the majority of South Asia (Figure 10c,d).

351 Figure 11 shows the JJAS mean low, middle, high, and total cloud cover from ISSCP 352 observations and simulations, as well as their differences. In DefCAM5, the low, middle, and high 353 clouds are all overestimated over the Indian land, western and equatorial Indian ocean (Figure 11e354 g). However, in StochCAM5 (Figure 11i-k), these overestimations are reduced, particularly in the 355 middle clouds, which are reduced by more than $10 \%$ over the western and equatorial Indian ocean, 356 and the high clouds, which are reduced by more than 5\% over the Indian land (Figure 11m-o).

357 Thus, the pattern of changes in total clouds is dominated by the changes in middle clouds over the 358 western and equatorial Indian ocean and high clouds over the Indian land (Figure 11p). These 359 changes in the cloud cover in StochCAM5 can also be seen from a relative decrease in relative 
360 humidity in middle and high levels (Figure 6f) and the reduced rate of heating and drying the

361 troposphere over $40^{\circ}-70^{\circ} \mathrm{E}$ from the moist processes (Supp. Figure S5). This reduced rate of

362 heating and drying the troposphere is arising from the decreased convective updraft mass flux

363 (Figure not shown). Since changes in LWP, IWP, and cloud fraction influences the cloud radiative

364 effects, we find in Supp. Figure S6 that the large negative (positive) bias seen in DefCAM5 over

365 the western Indian ocean and AS in SWCF (LWCF) is significantly alleviated in StochCAM5,

366 with one possible reason being the reduced rate of heating and drying the troposphere (Jones et al.

367 2019b).

368

$369 \quad 3.4 \quad$ Low-level and Upper-level Wind

370 Since the changes in low-level and upper-level wind circulations during JJAS influence the

371 moisture transport and precipitation over the ISM region, and hence, we analyze the low-level (850

$372 \mathrm{hPa})$ and upper-level (200 hPa) wind circulations from ERA-I and simulations. Both model

373 simulations capture the prime features of low-level wind circulation seen in observation, although

374 with few biases in amplitude and spatial extent (Figure 12a-c). For example, the Somali jet (SJ)

375 and low-level westerly wind over peninsular India and BoB are weaker in DefCAM5, but they are

376 better simulated in StochCAM5 and comparable to ERA-I. In the upper-level wind circulation,

377 DefCAM5 shows a large underestimation in the tropical easterly jet (TEJ) and overestimation in

378 the subtropical westerly jet (STJ). In comparison to DefCAM5, the simulation of STJ is slightly

379 improved, and the simulation of TEJ is deteriorated in StochCAM5 (Figure 12:d-f).

380 To better understand the physical cause of these changes in wind circulation, we show the

381 annual cycle of $600-200 \mathrm{hPa}$ averaged meridional tropospheric temperature gradient (MTTG)

382 between the two boxes, one over $5^{\circ} \mathrm{N}-35^{\circ} \mathrm{N}$ and $40^{\circ} \mathrm{E}-100^{\circ} \mathrm{E}$ and other over $5^{\circ} \mathrm{N}-15^{\circ} \mathrm{S}$ and $40^{\circ} \mathrm{E}-$ 

$100^{\circ} \mathrm{E}$ (Figure 13). These two boxes represent the large-scale temperature gradient zones that are

384 responsible for the wind reversal from north-easterly to south-westerly and maintaining the south385 westerly wind flow during JJAS (e.g., Webster et al. 1998; Goswami and Xavier 2005; Goswami 386 and Chakravorty 2017). Overall, both model simulates MTTG comparable to ERA-I, but the 387 MTTG reversal from negative to positive and (positive to negative) is $\sim 10$ days earlier in 388 DefCAM5 as compared to the observed negative to positive (positive to negative) reversal in $\sim 1^{\text {st }}$ 389 June $\left(\sim 1^{\text {st }}\right.$ October $)$, making the monsoon circulation weaker followed by an early onset and 390 withdrawal of monsoon by $\sim 10$ days. The monsoon onset and withdrawal date are defined when 391 MTTG annual cycle changes from negative to positive and positive to negative value, respectively 392 (Goswami and Chakravorty 2017). On the other hand, StochCAM5 simulates the annual cycle of 393 MTTG very similar to ERA-I, except the reversal of negative to positive that is still earlier $\sim 8$ days 394 (Figure 13). In StochCAM5, the reversal of MTTG from positive to negative is simulated similarly 395 to ERA-I, resulting in a monsoon withdrawal close to the observed date $\left(\sim 1^{\text {st }}\right.$ October) (e.g., Xavier 396 et al. 2007; Ashfaq et al. 2009). This improvement in MTTG annual cycle in StochCAM5 is 397 thought to be a possible reason for an improvement in SJ and low-level westerly wind. These 398 MTTG changes may be attributed to enhanced regional Hadley circulation (Figure not shown) that 399 improves the meridional and vertical energy transport (Gadgil 2018). Supp. Figure S7 shows the 400 spatial pattern of JJAS mean tropospheric temperature averaged over 700-300 hPa for ERA-I and 401 model simulations. As compared to DefCAM5, StochCAM5 shows a 0.5 K increase in warm bias 402 over the Tibetan region and a $0.25 \mathrm{~K}$ increase in cold bias over the southern Indian ocean, 403 indicating an increased north-south temperature gradient and thus a small increase in MTTG peak 404 during JJAS (Figure 13). 


\subsection{North-South Wavenumber-Frequency Spectrum}

The pronounced 30-60 day oscillations of northward propagating convection anomalies from EIO to ISM region during JJAS is recognized as a unique feature of monsoon intra-seasonal

409 oscillation (MISO; Joseph et al. 2009; Joseph et al. 2012; Suhas et al. 2012; Abhik et al. 2013;

410 Sharmila et al. 2013; Abhilash et al. 2014). It accounts for $~ 20 \%$ of total rainfall variance over the

411 Indo-Pacific region and linked to active and break spells of ISM (e.g., Goswami et al. 2011; Suhas

412 et al. 2013). Hence, the north-south wavenumber frequency spectrum is analyzed during JJAS over

413 the ISM region $\left(65^{\circ} \mathrm{E}-90^{\circ} \mathrm{E} ; 15^{\circ} \mathrm{S}-30^{\circ} \mathrm{N}\right)$ to investigate how well the DefCAM5 and StochCAM5

414 simulate MISO in comparison to observations. Figure 14a-c shows JJAS north-south space-time

415 spectra of daily precipitation from TRMM and simulations. TRMM shows a dominant northward

416 propagating mode of 30-60 day period at wavenumber 1 with maximum power at 45 days (Figure

417 14a). Compared to TRMM, DefCAM5 failed to capture the MISO signal at wavenumber 1 (Figure

418 14b), while StochCAM5 captures it at wavenumber 1 with maximum power at $~ 50$ days (Figure

419 14c). Further, we compute the ratio of northward and southward power of the precipitation

420 spectrum averaged over 30-90 day period to verify the fraction of meridionally propagating MISO

421 (Figure 14d-f). TRMM shows that the northward power is greater than the southward power at

422 wavenumber 1, while the northward and southward power are nearly equal at all other

423 wavenumbers. DefCAM5 failed to simulate the correct ratio as noticed before, exhibiting higher

424 power for southward not only at wavenumber 1 but also at wavenumber 2 . On the other hand,

425 StochCAM5 simulates greater power in northward than southward at wavenumber 1 and 2, but the 426 simulated power is lesser than TRMM.

427 Furthermore, from the analysis of underlying mechanisms for MISO, we find that the 428 MISO improvement in StochCAM5 is likely due to the improvement in the simulation of 
429 atmospheric internal dynamics associated with vertical easterly wind shear over the Indian

430 latitudes (Supp. Figure S8; e.g., Jiang et al. 2004; Drbohlav and Wang 2005; Sharmila et al. 2013),

431 and this improvement in MISO could be another reason for the improvements in seasonal mean

432 rainfall (e.g., Abhik et al. 2013; Abhilash et al. 2014).

\section{$434 \quad 3.6 \quad$ East-West Wavenumber-Frequency Spectrum}

Figure 15 shows the symmetric component of the normalized power spectrum of daily total

436 precipitation averaged over $15^{\circ} \mathrm{S}-15^{\circ} \mathrm{N}$ during JJAS from TRMM and simulations, using the

437 methodology of Wheeler and Kiladis (1999). This figure shows the eastward and westward

438 propagation of convective anomalies associated with MJO and equatorial waves (e.g., Kelvin and

439 Rossby waves). Previous studies have shown that the zonally (east-west) propagating disturbances

440 travel along the equator and significantly affect the synoptic variability in the tropics. Thus, from

441 figure 15, for MJO, the observed eastward propagating mode with 30-70 days period and wave

442 number $1-5$ is found to be weaker simulated (shorter in periodicity and lesser in power, with

443 maximum power only in the zonal wavenumber range of 1-1.5) in DefCAM5, while, it is found to

444 be better simulated with enhancement in power in the zonal wavenumber range of 1-4 in

445 StochCAM5 with an average periodicity of $\sim 30-70$ days. This improvement is expected to be

446 arising from increased shallow convection (Zhang and Mu 2005), which helps to precondition the

447 lower troposphere for MJO (e.g., Zhang and Song 2009; Wang et al. 2016b). The power of

448 eastward propagating Kelvin wave is found to be better simulated for lower frequencies (5-25

449 days) at shorter zonal wave-numbers, but the power at higher frequencies for higher zonal wave-

450 numbers is even more underestimated in StochCAM5. Furthermore, for the Rossby wave, a 451 westward propagating wave with periodicity 10-45 days and zonal wavenumber (-1 to -10$)$ is 
452 simulated comparable to TRMM, however, the spectral power at smaller zonal wavenumber (-1 to

$453-6)$ is slightly underestimated in both model simulations.

\section{$455 \quad 4 . \quad$ Conclusions}

456 In this study, we modified the deterministic ZMNR deep convection parameterization

457 scheme by stochastically formulating the entrainment rate. Two simulations, one with default 458 scheme (DefCAM5) and other with modified scheme (StochCAM5), were performed using 459 NCAR-CAM5. Statistical evaluation metrics computed for these simulations showed that 460 StochCAM5 outperforms DefCAM5 in simulating mean annual and seasonal climate states on 461 both global and regional scales (South Asia). Specifically, StochCAM5 significantly alleviates the

462 South Asian summer monsoon related biases, such as:

463 - The total precipitation overestimation over AS, northeast India, EIO, MC, and the underestimation over central India, BoB, Burmese mountains, Myanmar, and WPO

- The early retreat of monsoon from Indian land

These biases have been longstanding concerns in climate modeling, and their improvement will

469 play a crucial role in the simulation of the current climate, process studies, and future climate

470 change projections (e.g., Sperber et al. 2013; Sabeerali et al. 2014; Wang et al. 2018). These

471 improvements in StochCAM5 are due to improved representation of convective clouds by 472 launching clouds with stochastic entrainment rates. In addition to total precipitation, StochCAM5 473 also improves its partitioning between convective and large-scale precipitation components. 474 Improvement in convective precipitation is through the large change in deep- and moderate change 
475 in shallow-convective precipitation, while improvement in large-scale precipitation is through 476 improved cloud microphysical properties via LWP (Morrison and Gettelman 2008). Cloud forcing, 477 cloud cover fractions, relative humidity, specific humidity, and precipitable water from 478 StochCAM5 are also considerably improved over South Asia for JJAS.

479 As for the above improvements, StochCAM5 also enhances the large-scale dynamics 480 associated with it. Improved SJ and low-level westerly wind boost the moisture transport from the 481 ocean to the Indian sub-continent (e.g., Findlater 1969), resulting in reduced precipitation biases. 482 The worsening of overestimated precipitation over peninsular India in StochCAM5 as compared 483 to DefCAM5 is due to the strengthening of TEJ and its influence on the low-level westerly jet, 484 thus causing more precipitation over peninsular India and less moisture transport over the core 485 monsoon region (Koteswaram 1958; Sathiyamoorthy 2005; Sreekala et al. 2013). Improvement in 486 large-scale MTTG through the enhancement of meridional and vertical energy transport (Gadgil 487 2018) could be the major reasons for the improvement in low-level wind circulation (e.g., 488 Goswami and Xavier 2005). This improvement in MTTG enhances the atmospheric instability and 489 convection over the core monsoon region (Zhou and Murtugudde 2014), and hence the 490 improvement in ITCZ (e.g., Gadgil 2018) and monsoon withdrawal (e.g., Xavier et al. 2007; 491 Ashfaq et al. 2009).

492 StochCAM5 has also substantially improved the simulation of MISO, MJO, and planetary493 scale equatorial Kelvin waves for higher periodicity days. Thus, we find that although the 494 implementation of stochasticity in cloud entrainment in the deep convection parameterization led 495 to the improvement in multiple climate phenomena, both globally and over South Asia, there still 496 remain biases, suggesting the need for further model development. 
499 Authors are greatly thankful to the Indian Ministry of Human Resource Development for providing 500 the Ph.D. fellowship to RP. Authors are also thankful to the supercomputing facility 501 (http://supercomputing.iitd.ac.in/), DST CoE in Climate Modeling (RP03350), and DST FIST 502 project of CAS at IIT Delhi for providing partial support in the form of computing resources. The 503 NCAR Community Atmosphere Model version-5 (CAM5) used for the model simulations and 504 NCAR-NCL6.4.0 used for data analysis are also acknowledged. Finally, we want to express our 505 gratitude to the five anonymous reviewers for their suggestions, which helped to improve the 506 manuscript.

508 Data Availability

509 The observed data used in this study is publicly available and the model simulated data can be 510 obtained from the corresponding author.

\section{Code Availability}

513 The climate model used for simulations are freely available at https://www.cesm.ucar.edu/ and the 514 code used for figure generation is available with corresponding author and can be obtained on 515 request.

\section{Conflict of interest}

518 The authors declare no competing interests. 


\section{References}

Abhik S, Halder M, Mukhopadhyay P, et al (2013) A possible new mechanism for northward propagation of boreal summer intraseasonal oscillations based on TRMM and MERRA reanalysis. Clim Dyn. https://doi.org/10.1007/s00382-012-1425-x

Abhilash S, Sahai AK, Borah N, et al (2014) Prediction and monitoring of monsoon intraseasonal oscillations over Indian monsoon region in an ensemble prediction system using CFSv2. Clim Dyn 42:2801-2815. https://doi.org/10.1007/s00382-013-2045-9

Adler RF, Huffman GJ, Chang A, et al (2003) The version-2 global precipitation climatology project (GPCP) monthly precipitation analysis (1979-present). J Hydrometeorol https://doi.org/10.1175/1525-7541(2003)004<1147:TVGPCP>2.0.CO;2

Anand A, Mishra SK, Sahany S, et al (2018) Indian Summer Monsoon Simulations: Usefulness of Increasing Horizontal Resolution, Manual Tuning, and Semi-Automatic Tuning in Reducing Present-Day Model Biases. Sci Rep 8:1-14. https://doi.org/10.1038/s41598-018-21865-1

Arnold NP, Kuang Z, and Tziperman E (2013) Enhanced MJO-like variability at high SST. J. Clim 26:988-1001. doi:10.1175/JCLI-D-12-00272.1.

Ashfaq M, Shi Y, Tung WW, et al (2009) Suppression of south Asian summer monsoon precipitation in the 21st century. Geophys Res Lett 36:1-5. https://doi.org/10.1029/2008GL036500

Bechtold P, Köhler M, Jung T, et al (2008) Advances in simulating atmospheric variability with the ECMWF model: From synoptic to decadal time-scales. QJRMS. https://doi.org/10.1002/qj.289

Benedict JJ, Randall DA (2009) Structure of the Madden-Julian Oscillation in the Superparameterized CAM. J Atmos Sci. https://doi.org/10.1175/2009jas3030.1

Benedict JJ, Randall DA (2011) Impacts of idealized air-Sea coupling on Madden-Julian oscillation structure in the superparameterized CAM. J Atmos Sci. https://doi.org/10.1175/JAS-D-11-04.1

Berner J, Shutts GJ, Leutbecher M, Palmer TN (2009) A spectral stochastic kinetic energy backscatter scheme and its impact on flow-dependent predictability in the ECMWF ensemble prediction system. J Atmos Sci. https://doi.org/10.1175/2008JAS2677.1

Boos WR, Kuang Z (2010) Dominant control of the South Asian monsoon by orographic insulation versus plateau heating. Nature. https://doi.org/10.1038/nature08707

Bretherton CS, Park S (2009) A new moist turbulence parameterization in the community atmosphere model. J Clim. https://doi.org/10.1175/2008JCLI2556.1

Bright DR, Mullen SL (2002) Short-range ensemble forecasts of precipitation during the Southwest monsoon. Weather Forecast. https://doi.org/10.1175/15200434(2002)017<1080:SREFOP>2.0.CO;2

Buizza R, Milleer M, Palmer TN (2007) Stochastic representation of model uncertainties in the ECMWF ensemble prediction system. QJRMS. https://doi.org/10.1002/qj.49712556006

Bush SJ, Turner AG, Woolnough SJ, et al (2015) The effect of increased convective entrainment on Asian monsoon biases in the MetUM general circulation model. QJRMS. https://doi.org/10.1002/qj.2371

Dash, SK. et al (2017) Climate Modeling in India: Present Status and the Way Forward. BAMS ES183ES188. https://doi.org/10.1175/BAMS-D-16-0322.1

Dee DP, Uppala SM, Simmons AJ, et al (2011) The ERA-Interim reanalysis: Configuration and performance of the data assimilation system. QJRMS 137:553-597. https://doi.org/10.1002/qj.828

DeMott CA, Stan C, Randall DA (2013) Northward propagation mechanisms of the boreal summer 
intraseasonal oscillation in the ERA-interim and SP-CCSM. J Clim. https://doi.org/10.1175/JCLI-D12-00191.1

DeMott CA, Stan C, Randall DA, et al (2011) The Asian monsoon in the superparameterized CCSM and

its relationship to tropical wave activity. J Clim. https://doi.org/10.1175/2011JCLI4202.1

Deng Q, Khouider B, Majda AJ (2015) The MJO in a coarse-resolution GCM with a stochastic multicloud parameterization. J Atmos Sci. https://doi.org/10.1175/JAS-D-14-0120.1

Dorrestijn J, Crommelin DT, Siebesma AP, Jonker HJJ (2013) Stochastic parameterization of shallow cumulus convection estimated from high-resolution model data. Theor Comput Fluid Dyn 27:133148. https://doi.org/10.1007/s00162-012-0281-y

Drbohlav HK-L, Wang B (2005) Mechanism of the northward propagating Intraseasonal oscillations: insight from a zonally symmetric model. J Clim 18:952-972

Findlater J (1969) A major low-level air current near the Indian Ocean during the northern summer. QJRMS. https://doi.org/10.1002/qj.49709540409

Gadgil S (2018) The monsoon system: Land-sea breeze or the ITCZ? J Earth Syst Sci 127:1-29. https://doi.org/10.1007/s12040-017-0916-x

Gettelman A, Liu X, Ghan SJ, et al (2010) Global simulations of ice nucleation and ice supersaturation with an improved cloud scheme in the Community Atmosphere Model. J Geophys Res Atmos 115:1-19. https://doi.org/10.1029/2009JD013797

Goswami BB, Khouider B, Phani R, et al (2017a) Improving synoptic and intraseasonal variability in CFSv2 via stochastic representation of organized convection. Geophys Res Lett. https://doi.org/10.1002/2016GL071542

Goswami BB, Khouider B, Phani R, et al (2017b) Improved tropical modes of variability in the NCEP Climate Forecast System (Version 2) via a stochastic multicloud model. J Atmos Sci. https://doi.org/10.1175/JAS-D-17-0113.1

Goswami BB, Krishna RPM, Mukhopadhyay P, et al (2015) Simulation of the Indian Summer Monsoon in the superparameterized Climate Forecast System Version 2: Preliminary results. J Clim. https://doi.org/10.1175/JCLI-D-14-00607.1

Goswami BN, Chakravorty S (2017) Dynamics of the Indian Summer Monsoon Climate. Oxford Research Encyclopedia of Climate Science. https://doi.org/10.1093/acrefore/9780190228620.013.613

Goswami BN, Wheeler M, Gottschalck JC, Waliser DE (2011) Intra-seasonal variability and forecasting: a review of recent research. The global monsoon system: research and forecast WMO 389-4.

Goswami BN, Xavier PK (2005) ENSO control on the south Asian monsoon through the length of the rainy season. Geophys Res Lett 32:1-4. https://doi.org/10.1029/2005GL023216

Grabowski WW, Smolarkiewicz PK (1999) CRCP: A Cloud Resolving Convection Parameterization for modeling the tropical convecting atmosphere. Phys D Nonlinear Phenom. https://doi.org/10.1016/S0167-2789(99)00104-9

Held IM, Zhao M, Wyman B (2007) Dynamic radiative-convective equilibria using GCM column physics. J Atmos Sci. https://doi.org/10.1175/JAS3825.11

Huffman GJ, Adler RF, Bolvin DT, et al (2007) The TRMM Multisatellite Precipitation Analysis (TMPA): Quasi-global, multiyear, combined-sensor precipitation estimates at fine scales. J Hydrometeorol. https://doi.org/10.1175/JHM560.1

Iacono MJ, Delamere JS, Mlawer EJ, et al (2008) Radiative forcing by long-lived greenhouse gases: Calculations with the AER radiative transfer models. J Geophys Res Atmos. 
https://doi.org/10.1029/2008JD009944

Jain S, Salunke P, Mishra SK, Sahany S (2019) Performance of CMIP5 models in the simulation of Indian summer monsoon. Theor Appl Climatol. https://doi.org/10.1007/s00704-018-2674-3

Jiang X, Li T, and Wang B (2004) Structures and mechanisms of the northward propagating boreal summer intraseasonal oscillation. J Clim 17:1022-1039. https://doi.org/10.1175/15200442(2004)017<1022:SAMOTN>2.0.CO;2.

Jiang X, Waliser DE, Li JL, Woods C (2011) Vertical cloud structures of the boreal summer intraseasonal variability based on CloudSat observations and ERA-interim reanalysis. Clim Dyn. https://doi.org/10.1007/s00382-010-0853-8

Jones TR, Randall DA (2011) Quantifying the limits of convective parameterizations. J Geophys Res Atmos. https://doi.org/10.1029/2010JD014913

Jones, TR, Randall DA, and Branson MD (2019a) Multiple-instance superparameterization. 1: Concept, and predictability of precipitation. JAMES 11:3497-3520. https://doi.org/10.1029/2019ms001610

Jones, TR, Randall DA, and Branson MD (2019b Multiple-instance superparameterization: 2. The effects of stochastic convection on the simulated climate. JAMES 11:3521-3544. https"://doi.org/10.1029/2019MS001611

Joseph S, Sahai AK, Goswami BN (2009) Eastward propagating MJO during boreal summer and Indian monsoon droughts. Clim Dyn 32:1139-1153. doi:10.1007/s00382-008-0412-8

Joseph S, Sahai AK, Goswami BN, Terray P, Masson S, Luo JJ (2012) Possible role of warm SST bias in the simulation of boreal summer monsoon in SINTEX-F2 coupled model. Clim Dyn 38:1561-1576. doi:10.1007/s00382-011-1264-1

Joshi MM, Webb MJ, Maycock AC, Collins M (2010) Stratospheric water vapour and high climate sensitivity in a version of the HadSM3 climate model. Atmos Chem Phys. https://doi.org/10.5194/acp-10-7161-2010

Khairoutdinov MF, Randall DA (2001) A cloud resolving model as a cloud parameterization in the NCAR community climate system model: Preliminary results. Geophys Res Lett. https://doi.org/10.1029/2001GL013552

Khouider B, and Majda A J (2006) A simple multicloud parameterization for convectively coupled tropical waves. Part I: Linear analysis. J Atmos Sci 63(4):1308-1323.

Khouider B, Biello J, Majda AJ (2010) A stochastic multicloud model for tropical convection. Commun Math Sci. https://doi.org/10.4310/cms.2010.v8.n1.a10

Knight CG, Knight SHE, Massey N, et al (2007) Association of parameter, software, and hardware variation with large-scale behavior across 57,000 climate models. Proc Natl Acad Sci USA. https://doi.org/10.1073/pnas.0608144104

Kooperman GJ, Pritchard MS, O'Brien TA, and Timmermans BW (2018) Rainfall from resolved rather than parameterized processes better represents the present-day and climate change response of moderate rates in the community atmosphere model. JAMES 10:971-988. https://doi.org/10.1002/2017MS001188

Koteswaram P (1958) The Easterly Jet Stream in the Tropics. Tellus. https://doi.org/10.3402/tellusa.v10i1.9220

Krishnamurthy V, Stan C, Randall DA, et al (2014) Simulation of the South Asian monsoon in a coupled model with an embedded cloud-resolving model. J Clim. https://doi.org/10.1175/JCLI-D-1300257.1

\footnotetext{
Kummerow C, Barnes W, Kozu T, et al (1998) The Tropical Rainfall Measuring Mission (TRMM) sensor
} 
package. J Atmos Ocean Technol. https://doi.org/10.1175/15200426(1998)015<0809:TTRMMT>2.0.CO;2

Langan R, Archibald R, Plumlee M, et al (2014) Stochastic Parameterization to Represent Variability and Extremes in Climate Modeling. Procedia Comput Sci. https://doi.org/10.1016/j.procs.2014.05.103

Li C, Yanai M (1996) The onset and interannual variability of the asian summer monsoon in relation to land-sea thermal contrast. J Clim. 9:358-375

Li Y, et al (2018) The Indian Summer Monsoon Intraseasonal Oscillations in CFSv2 Forecasts: Biases and Importance of Improving Air-Sea Interaction Processes. J Clim 31(14): 5351-5370. https://doi.org/10.1175/JCLI-D-17-0623.1

Lin JWB, Neelin JD (2003) Toward stochastic deep convective parameterization in general circulation models. Geophys Res Lett 30:1-4. https://doi.org/10.1029/2002GL016203

Lin SJ (2004) A "vertically Lagrangian" finite-volume dynamical core for global models. Mon Weather Rev. https://doi.org/10.1175/1520-0493(2004)132<2293:AVLFDC>2.0.CO;2

Liu X et al (2007) (Inclusion of Ice Microphysics in the NCAR Community Atmospheric Model Version 3 (CAM3). J Clim 20(18):4526-4547. https://doi.org/10.1175/JCLI4264.1

Loeb NG et al (2009) Toward optimal closure of the earth's top-of-atmosphere radiation budget. J. Clim. 22(3):748-766.

Madden RA, and Julian PR (1971) Detection of a 40-50 day oscillation in the zonal wind in the tropical Pacific. J Atmos Sci 28:702-708.

Mishra SK, Anand A, Fasullo J, Bhagat S (2018) Importance of the resolution of surface topography in Indian monsoon simulation. J Clim 31:4879-4898. https://doi.org/10.1175/JCLI-D-17-0324.1

Mlawer EJ et al (1997) Radiative transfer for inhomogeneous atmospheres: RRTM, a validated correlated-k model for the longwave. J Geophys Res 102(14): 16663-16682.

Moncrieff MW, Waliser DE, Miller MJ, et al (2012) Multiscale convective organization and the YOTC virtual global field campaign. BAMS. https://doi.org/10.1175/BAMS-D-11-00233.1

Morrison H, Gettelman A (2008) A new two-moment bulk stratiform cloud microphysics scheme in the community atmosphere model, version 3 (CAM3). Part I: Description and numerical tests. J Clim. https://doi.org/10.1175/2008JCLI2105.1

Neale RB, Richter JH, Jochum M (2008) The impact of convection on ENSO: From a delayed oscillator to a series of events. J Clim. https://doi.org/10.1175/2008JCLI2244.1

Neggers RAJ, Siebesma AP, Jonker HJJ (2002) A multiparcel model for shallow cumulus convection. J Atmos Sci 59:1655-1668. https://doi.org/10.1175/1520-0469(2002)059<1655:AMMFSC >2.0.CO;2

Nie J, Kuang Z (2012) Responses of shallow cumulus convection to large-scale temperature and moisture perturbations: A comparison of large-eddy simulations and a convective parameterization based on stochastically entraining parcels. J Atmos Sci. https://doi.org/10.1175/JAS-D-11-0279.1

Oueslati B, Bellon G (2013) Convective entrainment and large-scale organization of tropical precipitation: Sensitivity of the CNRM-CM5 hierarchy of models. J Clim. https://doi.org/10.1175/JCLI-D-12-00314.1

Palmer TN (2001) A nonlinear dynamical perspective model error: A proposal for non-local stochasticdynamic parametrization in weather and climate prediction models. QJRMS. https://doi.org/10.1256/smsqj.57201

Park S, Bretherton CS (2009) The University of Washington shallow convection and moist turbulence schemes and their impact on climate simulations with the community atmosphere model. J Clim. https://doi.org/10.1175/2008JCLI2557.1 
Pathak R, Sahany S, Mishra SK, Dash SK (2019) Precipitation Biases in CMIP5 Models over the South Asian Region. Sci Rep. https://doi.org/10.1038/s41598-019-45907-4

Plant RS, Craig GC (2008) A stochastic parameterization for deep convection based on equilibrium statistics. J Atmos Sci 65:87-105. https://doi.org/10.1175/2007JAS2263.1

Pritchard MS, Bretherton CS, and DeMott CA (2014) Restricting 32-128 km horizontal scales hardly affects the MJO in the Superparameterized Community Atmosphere Model v.3.0 but the number of cloud-resolving grid columns constrains vertical mixing. JAMES 6:723-739. doi:10.1002/2014MS000340

Pritchard MS, Moncrieff MW, Somerville RCJ (2011) Orogenic propagating precipitation systems over the united states in a global climate model with embedded explicit convection. J Atmos Sci. https://doi.org/10.1175/2011JAS3699.1

Qian Y, Yan H, Hou Z, et al (2015) Parametric sensitivity analysis of precipitation at global and local scales in the Community Atmosphere Model CAM5. JAMES. https://doi.org/10.1002/2014MS000354

Randel DL, et al (1996) A new global water vapor dataset. BAMS 77(6):1233-1246.

Raymond DJ, Blyth AM (1986) A stochastic mixing model for non-precipitating cumulus clouds. J Atmos Sci 43:2708-2718

Richter JH and Rasch P (2008) Effects of Convective Momentum Transport on the Atmospheric Circulation in the Community Atmosphere Model, Version 3. J Clim 21(7):1487-1499 https://doi.org/10.1175/2007JCLI1789.1

Rio C, Hourdin F, Couvreux F, and Jam A (2010) Resolved versus parametrized boundary-layer plumes. Part II: Continuous formulations of mixing rates for mass-flux schemes. Bound.-Layer Meteor. 135:469-483.

Romps DM, Kuang Z (2010) Do undiluted convective plumes exist in the upper tropical troposphere? J Atmos Sci 67:468-484. https://doi.org/10.1175/2009JAS3184.1

Sabeerali CT, Rao SA, George G, et al (2014) Modulation of monsoon intraseasonal oscillations in the recent warming period. J Geophys Res. https://doi.org/10.1002/2013JD021261

Salunke P, Jain S, Mishra SK (2019) Performance of the CMIP5 models in the simulation of the Himalaya-Tibetan Plateau monsoon. Theor Appl Climatol. https://doi.org/10.1007/s00704-0182644-9

Sathiyamoorthy V (2005) Large scale reduction in the size of the Tropical Easterly Jet. Geophys Res Lett. https://doi.org/10.1029/2005GL022956

Sharmila S, Pillai PA, Joseph S, Roxy M, Krishna RPM, Chattopadhyay R, Abhilash S, Sahai AK, Goswami BN (2013) Role of ocean-atmosphere interaction on northward propagation of Indian summer monsoon intra-seasonal oscillations (MISO). Clim Dyn. doi:10.1007/s00382-013-1854-1

Sherwood SC, Bony S, Dufresne JL (2014) Spread in model climate sensitivity traced to atmospheric convective mixing. Nature. https://doi.org/10.1038/nature12829

Shutts G (2005) A kinetic energy backscatter algorithm for use in ensemble prediction systems. QJRMS. https://doi.org/10.1256/qj.04.106

Siebesma AP, Bretherton CS, Brown A, et al (2003) A large eddy simulation intercomparison study of shallow cumulus convection. J Atmos Sci. https://doi.org/10.1175/15200469(2003)60<1201:ALESIS>2.0.CO;2

Sperber KR, Annamalai H, Kang IS, et al (2013) The Asian summer monsoon: An intercomparison of CMIP5 vs. CMIP3 simulations of the late 20th century. Clim Dyn. https://doi.org/10.1007/s00382- 
012-1607-6

Sreekala PP, Bhaskara Rao S V., Arunachalam MS, Harikiran C (2014) A study on the decreasing trend in tropical easterly jet stream (TEJ) and its impact on Indian summer monsoon rainfall. Theor Appl Climatol. https://doi.org/10.1007/s00704-013-1049-z

Stan C, Khairoutdinov M, Demott CA, et al (2010) An ocean-atmosphere climate simulation with an embedded cloud resolving model. Geophys Res Lett. https://doi.org/10.1029/2009GL040822

Suhas E, Neena JM, Goswami BN (2012) An Indian monsoon intraseasonal oscillations (MISO) index for real time monitoring and forecast verification. Clim Dyn. doi:10.1007/s00382-012-1462-5

Sušelj K, Hogan TF, Teixeira J (2014) Implementation of a stochastic eddy-diffusivity/mass-flux parameterization into the Navy Global environmental model. Weather Forecast. https://doi.org/10.1175/WAF-D-14-00043.1

Sušelj K, Teixeira J, and Matheou G (2012) EDMF and shallow cumulus boundary layer: An updraft pdf multiple mass flux scheme. J Atmos Sci 69:1513-1533.

Sušelj K, Teixeira J, Chung D (2013) A unified model for moist convective boundary layers based on a stochastic eddy-diffusivity/mass-flux parameterization. J Atmos Sci 70:1929-1953. https://doi.org/10.1175/JAS-D-12-0106.1

Waliser DE et al (2012) The "year" of tropical convection (May 2008-April 2010): Climate variability and weather highlights. BAMS 93:1189-1218. doi:10.1175/2011BAMS3095.1

Wang Y, Zhang GJ (2016a) Global climate impacts of stochastic deep convection parameterization in the NCAR CAM5. JAMES. https://doi.org/10.1002/2016MS000756

Wang Y, Zhang GJ, Craig GC (2016b) Stochastic convective parameterization improving the simulation of tropical precipitation variability in the NCAR CAM5. Geophys Res Lett 43:6612-6619. https://doi.org/10.1002/2016GL069818

Wang Y, Zhang GJ, He YJ (2017) Simulation of precipitation extremes using a stochastic convective parameterization in the NCAR CAM5 under different resolutions. J Geophys Res Atmos 122:12,875-12,891. https://doi.org/10.1002/2017JD026901

Wang Y, Zhang GJ, Jiang Y (2018) Linking stochasticity of convection to large-scale vertical velocity to improve Indian Summer Monsoon simulation in the NCAR CAM5. J Clim. https://doi.org/10.1175/JCLI-D-17-0785.1

Webster PJ, Magaña VO, Palmer TN, et al (1998) Monsoons: Processes, predictability, and the prospects for prediction. J Geophys Res Ocean. https://doi.org/10.1029/97jc02719

Wheeler M, Kiladis GN (1999) Convectively Coupled Equatorial Waves: Analysis of Clouds and Temperature in the Wavenumber-Frequency Domain. J Atmos Sci. https://doi.org/10.1175/15200469(1999)056<0374:CCEWAO>2.0.CO;2

Xavier PK, Marzin C, Goswami BN (2007) An objective definition of the Indian summer monsoon season and a new perspective on the ENSO-monsoon relationship. QJRMS 133:496. https://doi.org/10.1002/qj

Yang B, Qian Y, Lin G, et al (2013) Uncertainty quantification and parameter tuning in the cam5 zhangmcfarlane convection scheme and impact of improved convection on the global circulation and climate. J Geophys Res Atmos 118:395-415. https://doi.org/10.1029/2012JD018213

Young A, et al (2018) The International Satellite Cloud Climatology Project H-Series climate data record product. Earth Syst Sci Data 10:583-593. https://doi.org/10.5194/essd-10-583-2018, 2018.

Zhang GJ, and Mu M (2005) Effects of modifications to the Zhang-McFarlane convection parameterization on the simulation of the tropical precipitation in the National Center for 

Atmospheric Research Community Climate Model, version 3. J Geophys Res 110:D09109. doi:10.1029/2004JD005617. Oscillation simulation. Geophys Res Lett 36:L09708. doi:10.1029/2009GL037340.

789 Zhang GJ, McFarlane NA (1995) Sensitivity of climate simulations to the parameterization of cumulus convection in the canadian climate centre general circulation model. Atmos - Ocean.

792 Zhou L, Murtugudde R (2014) Impact of northward-propagating intraseasonal variability on the onset of Indian summer monsoon. J Clim. https://doi.org/10.1175/JCLI-D-13-00214.1 
Table 1: List of statistical values computed over South Asia from observation/ERA-I, DefCAM5 and StochCAM5.

797

\begin{tabular}{|c|c|c|c|c|c|c|}
\hline & $\begin{array}{l}\text { Obs./ERA- } \\
\text { I Mean }\end{array}$ & $\begin{array}{l}\text { DefCAM5 } \\
\text { (StochCAM5) } \\
\text { Mean }\end{array}$ & $\begin{array}{l}\text { Pearson } \\
\text { Pattern } \\
\text { Correlation }\end{array}$ & $\begin{array}{l}\text { Normalized } \\
\text { Standard } \\
\text { Deviation }\end{array}$ & $\begin{array}{l}\text { Percentage } \\
\text { Bias }\end{array}$ & RMSE \\
\hline Land Rainfall & 3.91 & $4.62(\mathbf{5 . 0 2})$ & $0.68(\mathbf{0 . 7 0})$ & $1.16(\mathbf{1 . 3 3})$ & $17.95(\mathbf{2 9 . 2 9 )}$ & $3.37(3.73)$ \\
\hline Ocean Rainfall & 4.13 & $5.15(\mathbf{5 . 0 0})$ & $0.58(\mathbf{0 . 7 0})$ & $0.83(\mathbf{0 . 8 2})$ & 24.79 (21.58) & $2.83(\mathbf{2 . 4 3})$ \\
\hline SWCF & -50.35 & $-62.91(-59.98)$ & $0.81(\mathbf{0 . 8 3})$ & 1.09 (1.08) & $24.96(\mathbf{1 9 . 1 3 )}$ & $22.67(\mathbf{2 0 . 2 6})$ \\
\hline LWCF & 35.59 & 35.19 (32.61) & $0.82(\mathbf{0 . 8 6})$ & $0.89(\mathbf{0 . 8 2})$ & $-1.11(\mathbf{- 8 . 3 5 )}$ & $12.14(\mathbf{1 1 . 0 3})$ \\
\hline Land 2-m Temperature & 24.02 & $24.74(\mathbf{2 4 . 8 0})$ & $0.94(\mathbf{0 . 9 4})$ & $1.04(\mathbf{1 . 0 7})$ & $2.97(\mathbf{3 . 2 5})$ & $2.73(2.77)$ \\
\hline $\mathrm{T}(1000-100 \mathrm{hPa})$ & 26.56 & 24.65 (24.69) & $0.46(\mathbf{0 . 4 7 )}$ & 1.35 (1.38) & $-7.21(-7.05)$ & $5.18(5.21)$ \\
\hline \multicolumn{7}{|l|}{ Relative Humidity (1000- } \\
\hline $100 \mathrm{hPa})$ & 71.78 & 72.09 (71.92) & $0.91(\mathbf{0 . 9 1 )}$ & $0.99(\mathbf{1 . 0 0})$ & $0.45(\mathbf{0 . 2 0})$ & $7.46(7.39)$ \\
\hline Zonal Wind at U850 & 4.36 & $-0.23(.05)$ & $0.95(\mathbf{0 . 9 6 )}$ & $1.08(\mathbf{1 . 1 2})$ & $-105.36(\mathbf{9 8 . 8 3})$ & $4.88(\mathbf{4 . 6 5 )}$ \\
\hline Vertical Wind at $500 \mathrm{hPa}$ & -0.027 & $-0.017(-\mathbf{0 . 0 2})$ & $0.36(\mathbf{0 . 4 0 )}$ & $0.70(\mathbf{0 . 7 3})$ & $-35.65(-37.49)$ & $0.05(\mathbf{0 . 0 5})$ \\
\hline
\end{tabular}




\section{Figures}

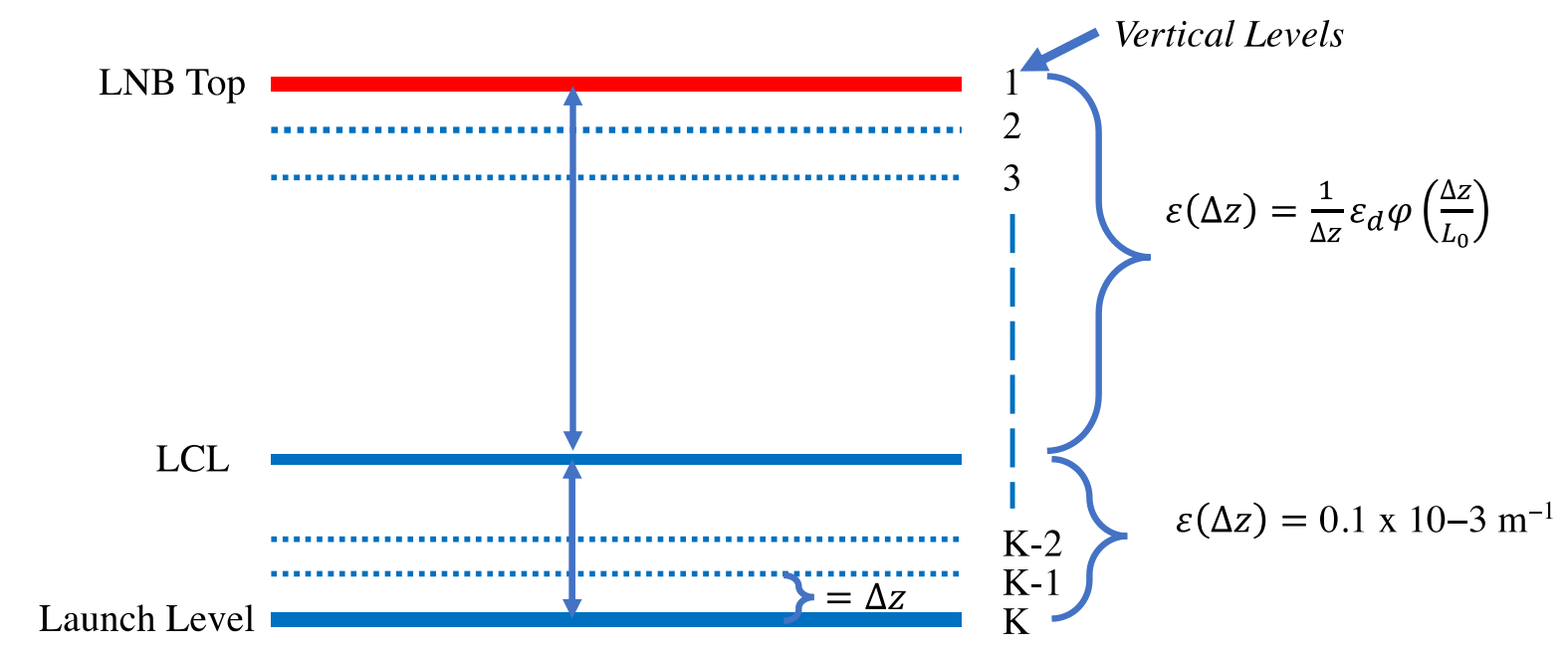

Figure 1: Structure of the stochastic entrainment rate implemented in the ZMNR deep convection

803 scheme. Entrainment rate ( $\varepsilon$ ) from the parcel launch level to lifting condensation level (LCL) is

804 kept the same as default value $\varepsilon(\Delta z)=0.1 \times 10-3 \mathrm{~m}^{-1}$. Entrainment above LCL is stochastically

805 computed until the level of neutral buoyancy (LNB). The levels used here are the default model

806 levels and the distance $\Delta z$ is the difference between the two model levels . 


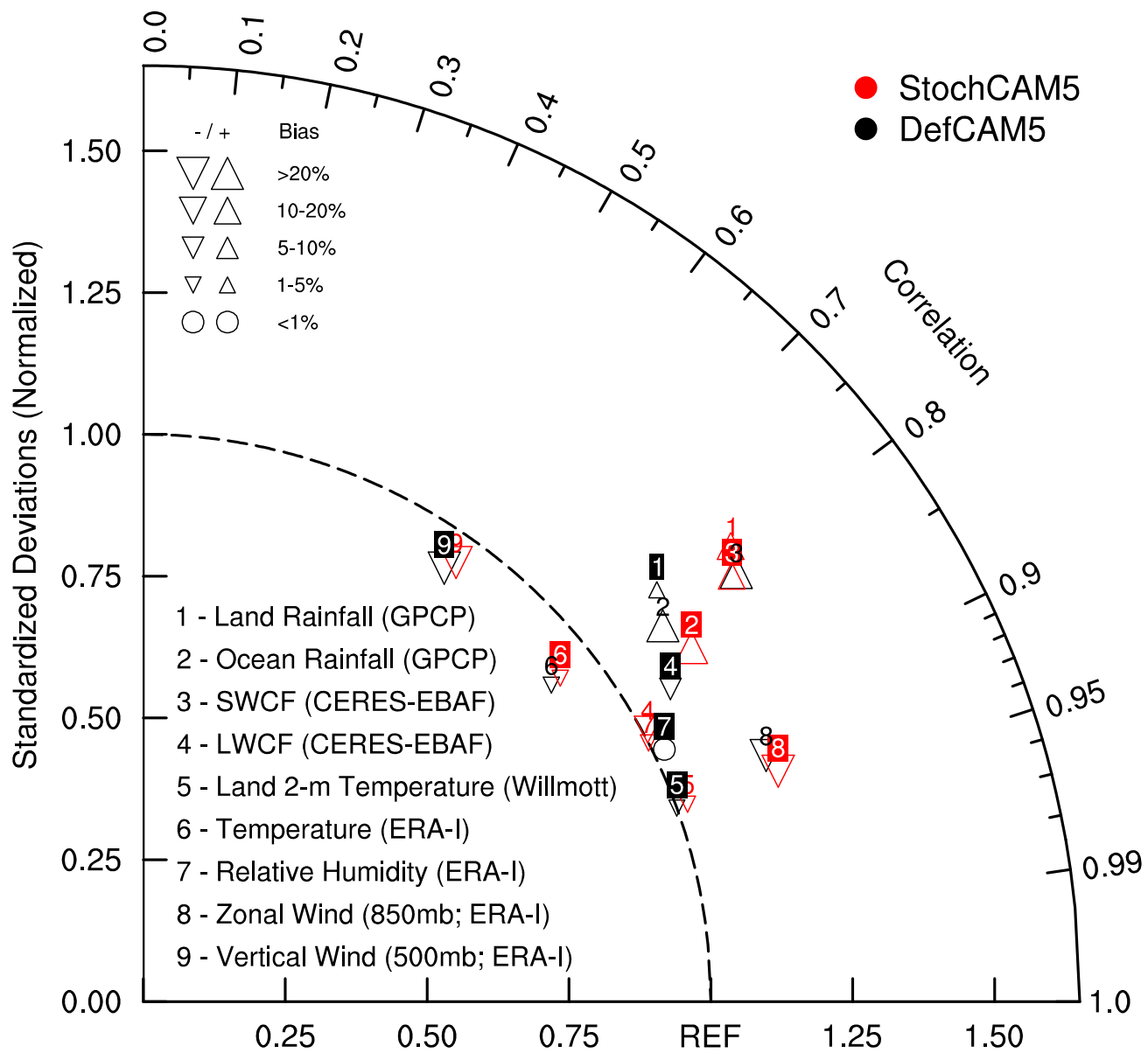

808 Figure 2: Taylor diagram with metrics for DefCAM5 and StochCAM5 over the tropics $\left(30^{\circ} \mathrm{S}-\right.$

$80930^{\circ} \mathrm{N}$ ). The specific humidity (point 6) and temperature (point 7) are the mass-weighted vertical

810 average from 1000-100 $\mathrm{hPa}$. The four metrics used here are the Pearson correlation coefficient

811 (represented by the cosine of the angle from the horizontal axis), the centered root mean square

812 error (represented by the distance from the point on the horizontal axis defined as the reference

813 point or REF), the normalized standard deviation (represented by the radial distance from the

814 origin), and the percentage error (represented by the size of markers). 

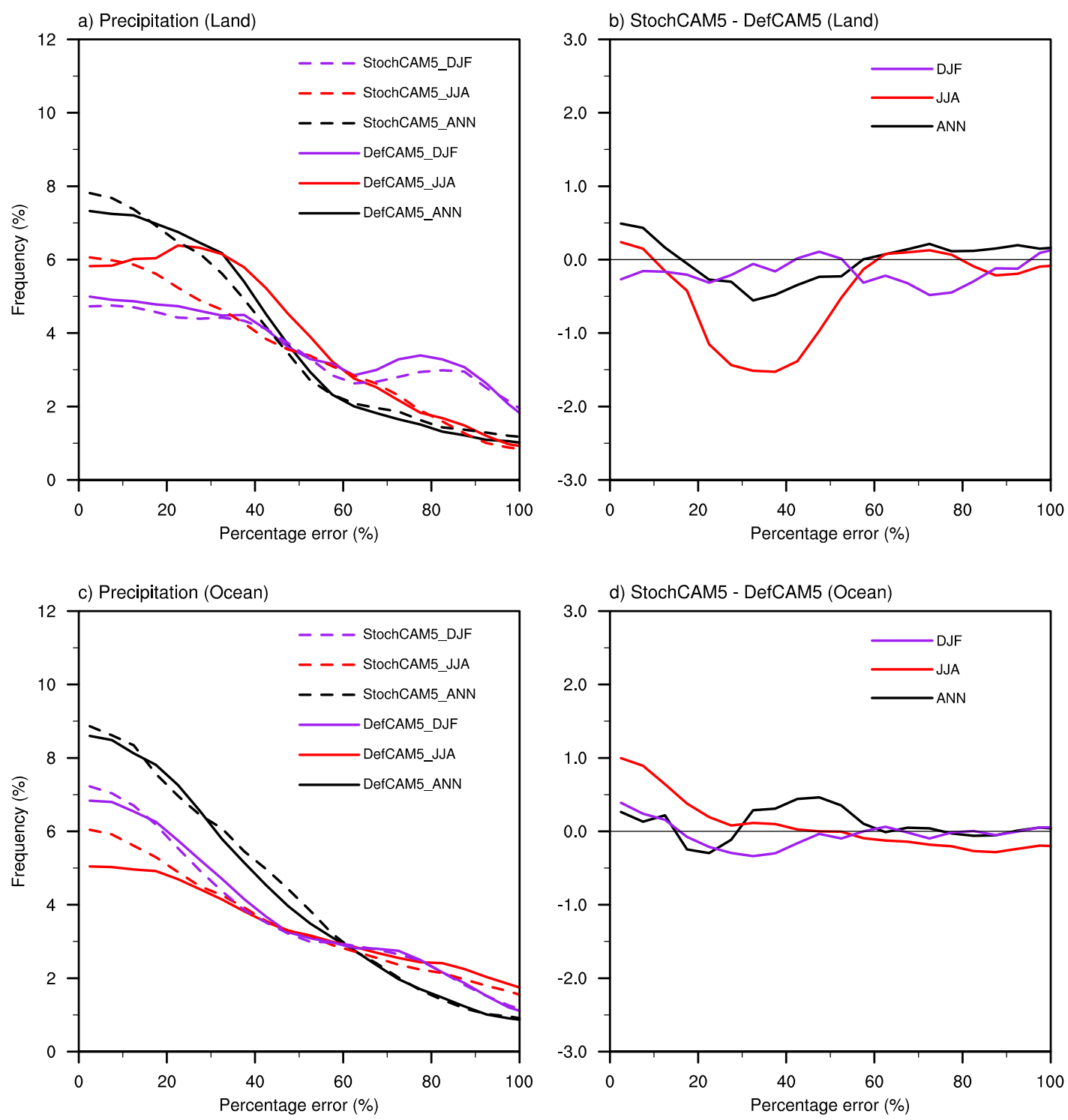

817 Figure 3: The frequency distribution of percentage bias for annual and seasonal (JJA and DJF) 818 mean precipitation over the tropical land and ocean $\left(30^{\circ} \mathrm{S}-30^{\circ} \mathrm{N}\right)$ from DefCAM5 and 819 StochCAM5, as well as their differences. The 5\% bin interval is used in computing the frequency of percentage bias. 

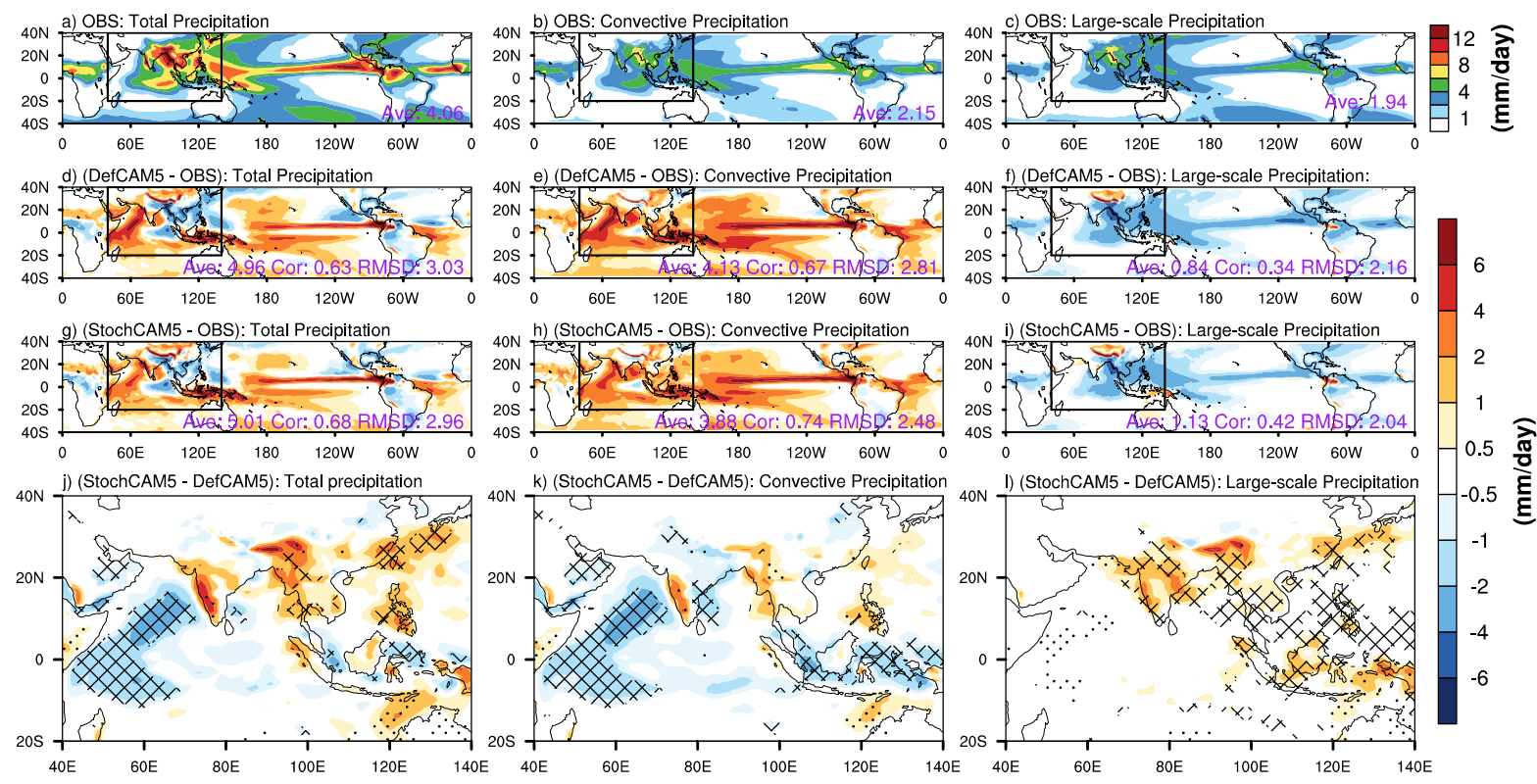

821 Figure 4: Spatial variation of JJAS mean precipitation. a-c shows the JJAS mean (a) total 822 precipitation, (b) convective precipitation and c) large-scale precipitation from GPCP observations

823 over the tropics. d-f and g-i shows the difference in total, convective, and large-scale precipitation

824 for DefCAM5 and StochCAM5 with respect to observations, respectively over the tropics. $\mathbf{j}-\mathbf{I}$

825 shows the difference in total, convective, and large-scale precipitation for StochCAM5 with 826 respect to DefCAM5 over South Asia (the zoomed region in black rectangle). The average value 827 (Ave.), correlation (Corr.), and the root mean square difference (RMSD) for precipitation over 828 South Asia are also shown at the bottom of a-i. Hatching (stippling) shows the differences which 829 are improved (deteriorated) at 95\% confidence level (two-tailed student t-test) in StochCAM5 with 830 respect to DefCAM5. 

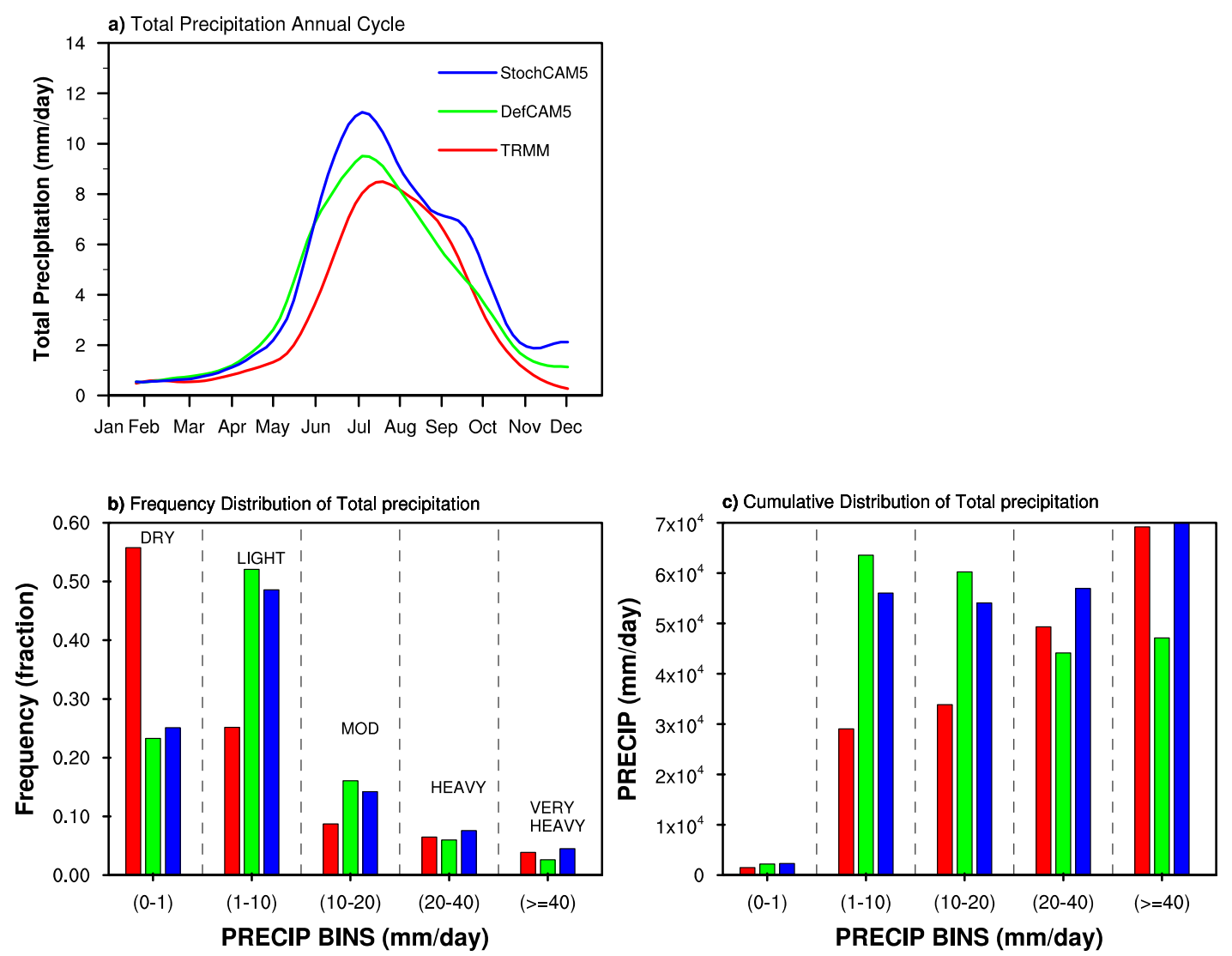

832 Figure 5: (a) annual total precipitation cycle, (b) frequency distribution of daily precipitation rate 833 over the Indian land during JJAS, and c) amount of precipitation falling in each bin of precipitation 834 rate over the Indian land during JJAS. 

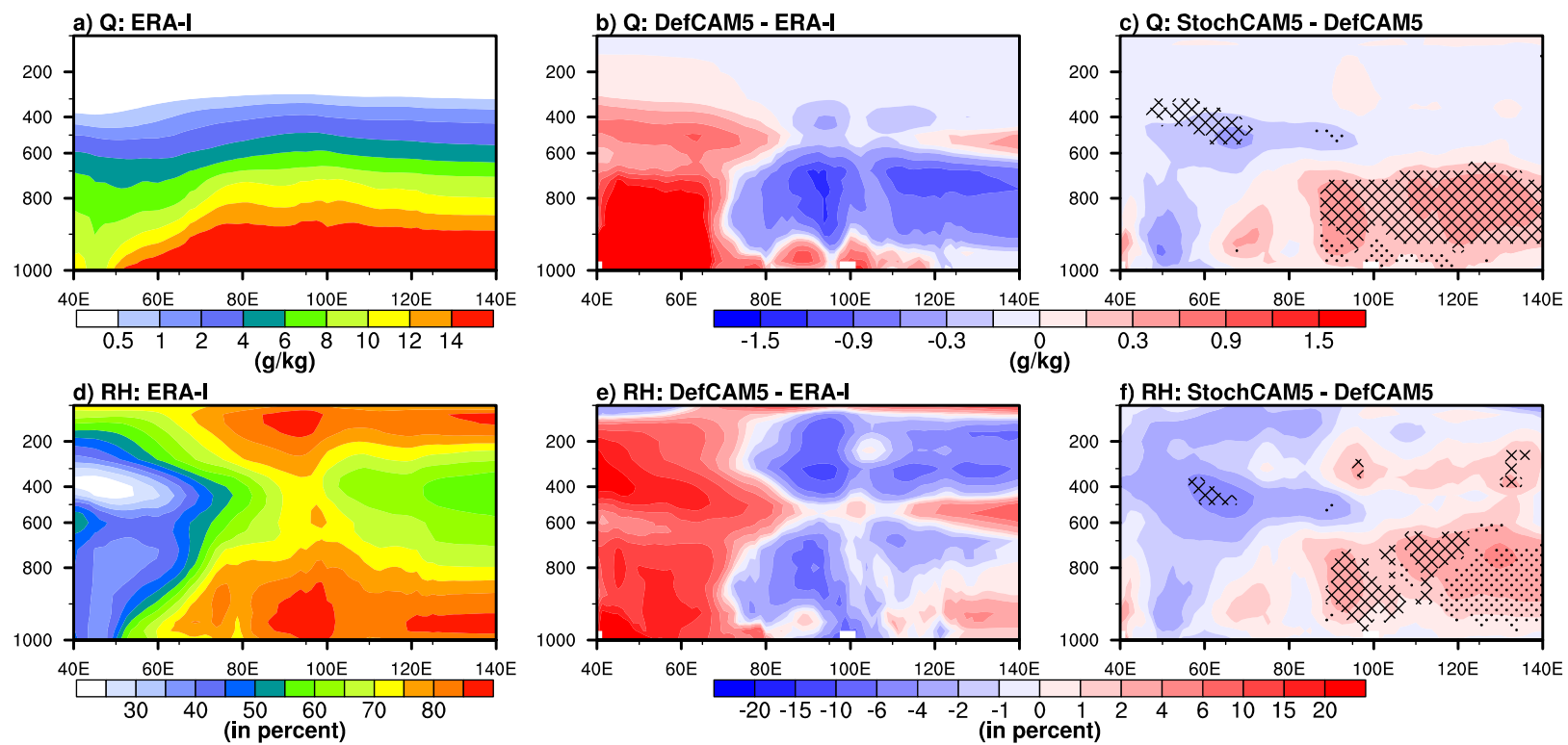

837 Figure 6: The JJAS meridional mean cross sections of (a-c) specific humidity and (d-f) relative

838 humidity in belt of Indian latitudes $\left(0^{\circ}-30^{\circ} \mathrm{N}\right)$ for (a, d) ERA-I, (b, e) DefCAM5 -ERA-I, and (c,

839 f) StochCAM5 -DefCAM5. Hatching (stippling) shows the differences which are improved

840 (deteriorated) at 95\% confidence level in StochCAM5 with respect to DefCAM5. Q - specific

841 humidity; $\mathrm{RH}$ - relative humidity.
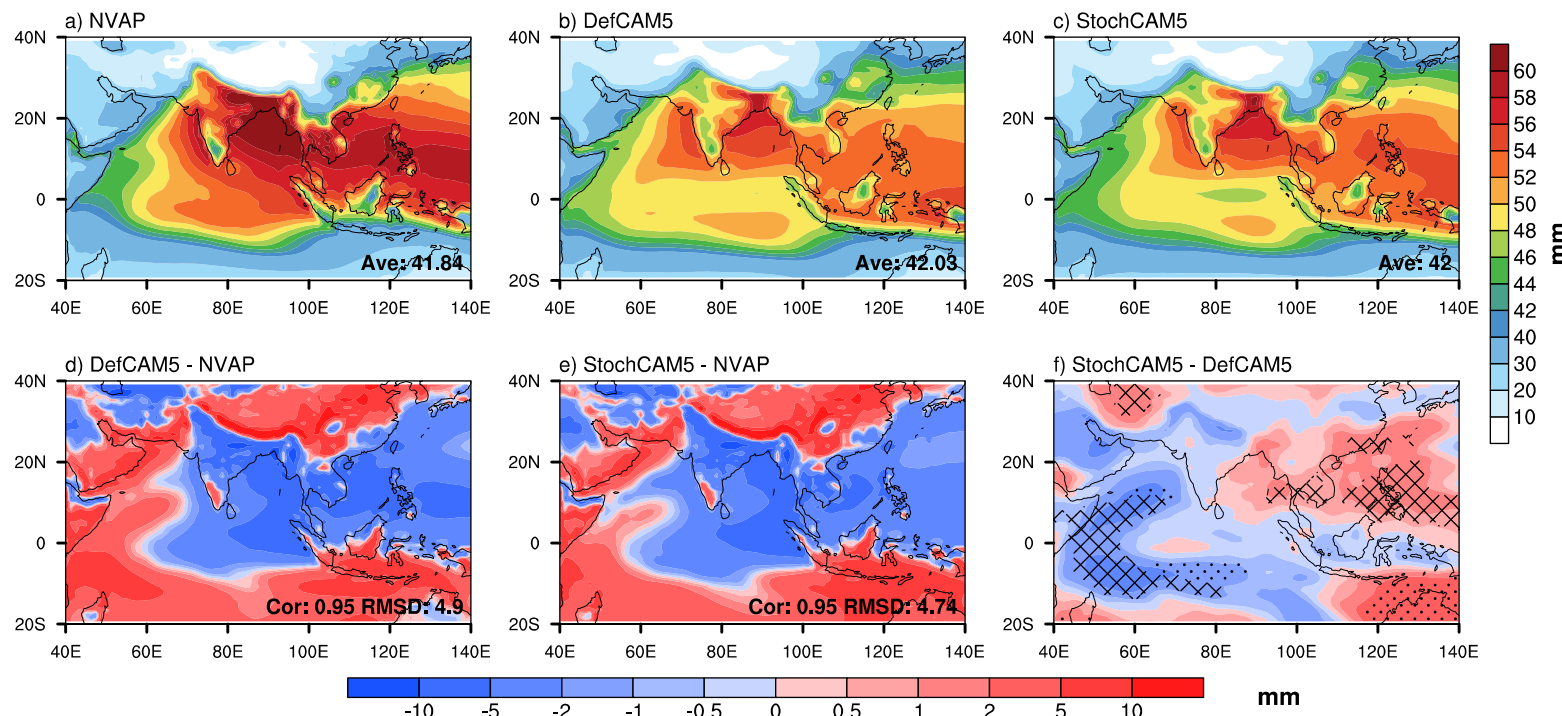
845 Figure 7: JJAS mean total column water vapor over South Asia for (a) NVAP, (b) DefCAM5, and 846 (c) StochCAM5 as well as their differences for (d) DefCAM5 - NVAP, (e) StochCAM5 - NVAP, 847 and (f) StochCAM5 - DefCAM5. Hatching (stippling) shows the differences which are improved 848 (deteriorated) at 95\% confidence level in StochCAM5 with respect to DefCAM5. NVAP 849 National Aeronautics and Space Administration (NASA) Water Vapor Project.

850
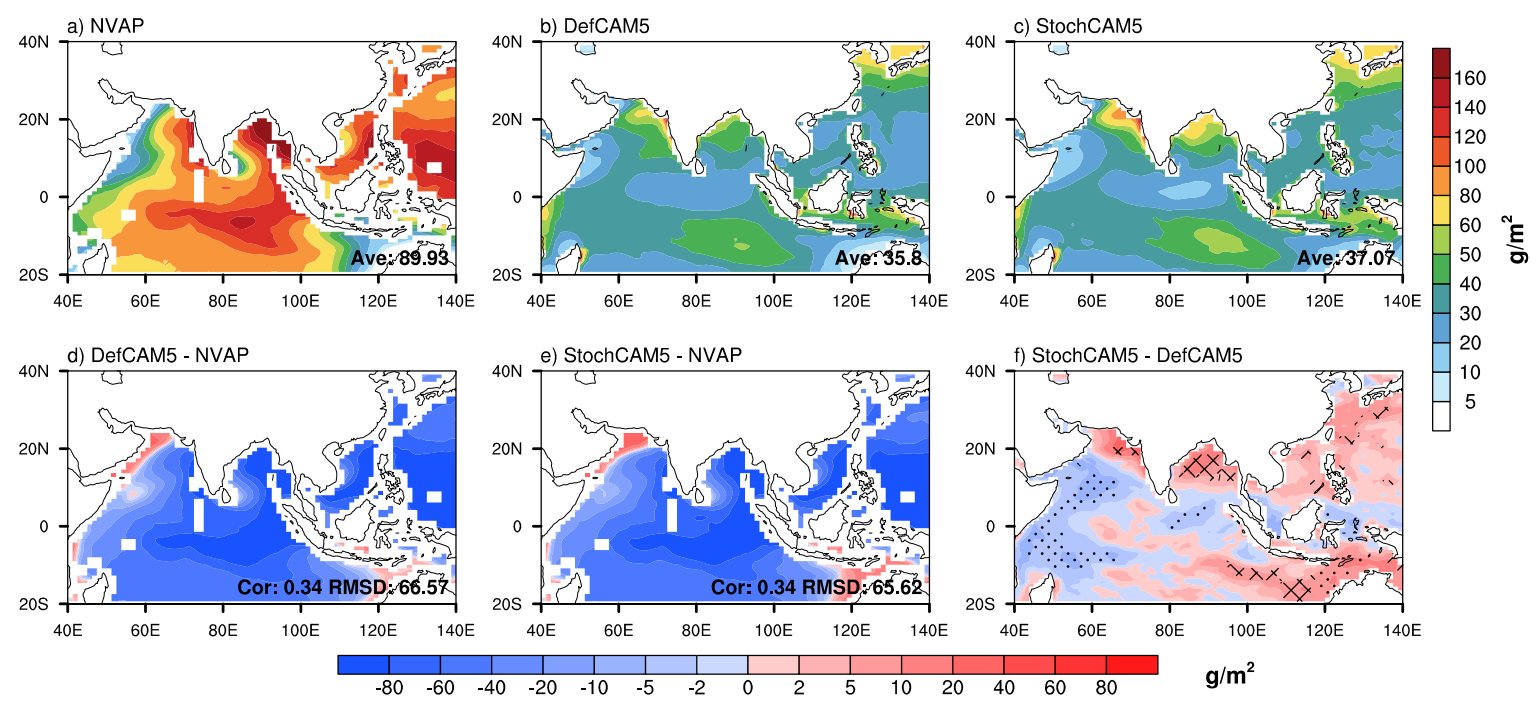

851

852 Figure 8: JJAS mean total liquid water path (LWP) over South Asia for (a) NVAP, (b) DefCAM5, 853 and (c) StochCAM5 as well as their differences for (d) DefCAM5 - NVAP, (e) StochCAM5 854 NVAP, and (f) StochCAM5 - DefCAM5. Hatching (stippling) shows the differences which are 855 improved (deteriorated) at 95\% confidence level in StochCAM5 with respect to DefCAM5. 


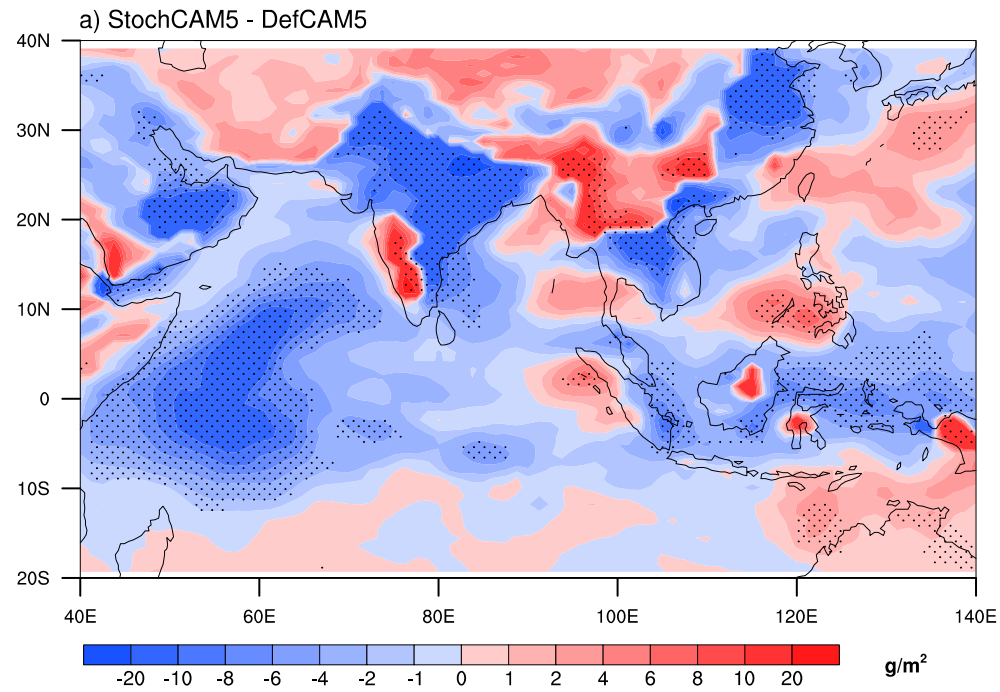

858 Figure 9: JJAS mean difference of ice water path (IWP) over South Asia between StochCAM5 859 and DefCAM5. The stippled regions show the differences which are significant at 95\% confidence 860 level.

861
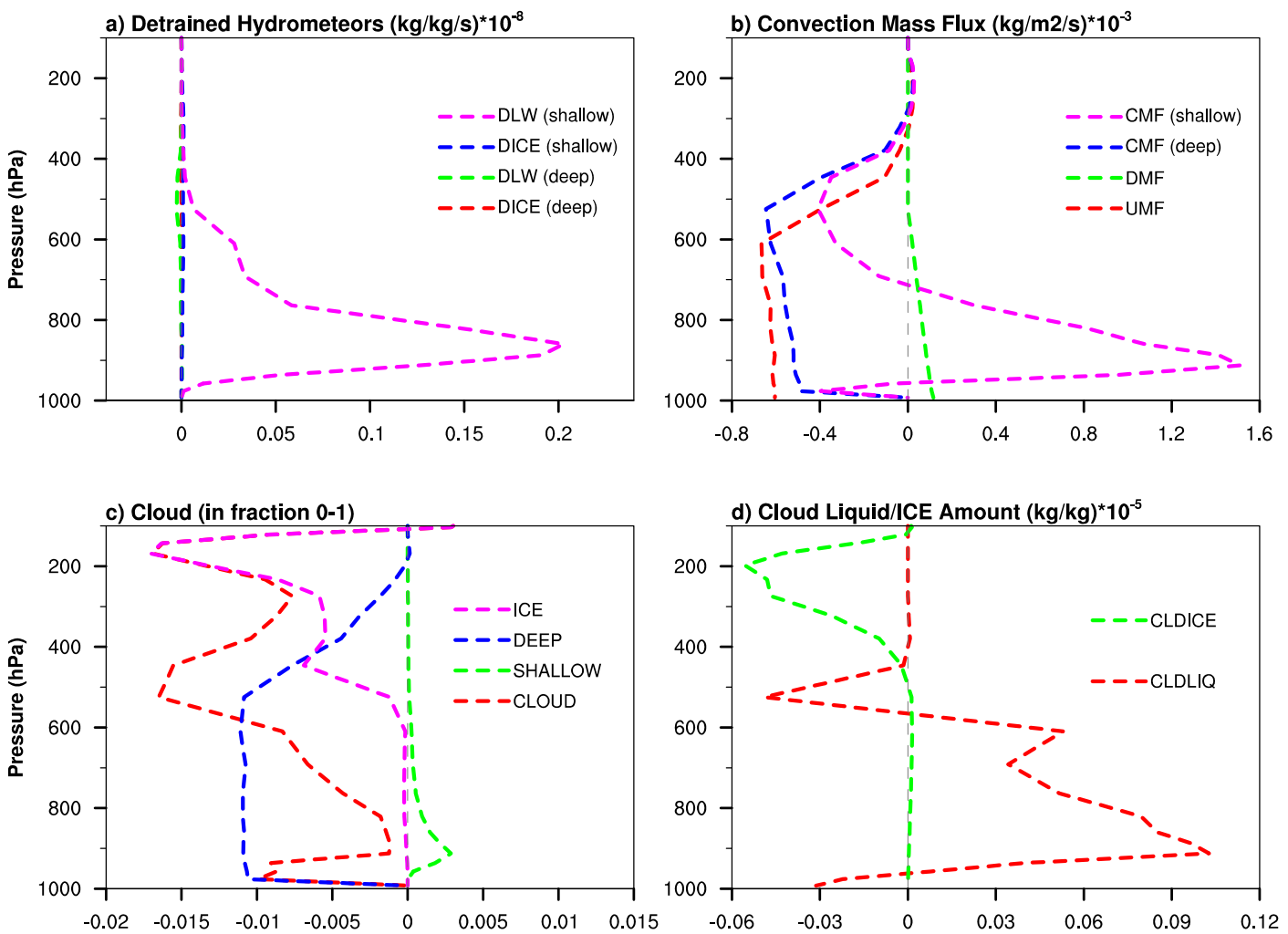
863 Figure 10: JJAS mean difference of (a) detrained liquid water (DLW) and detrained ice (DICE)

864 from deep and shallow convection, (b) updraft mass flux (UMF), downdraft mass flux (DMF), 865 convective mass flux (CMF) for shallow and deep convection, (c) cloud cover distribution of ice, 866 deep, shallow, and total cloud, and (d) cloud liquid and cloud ice amount over South Asia.
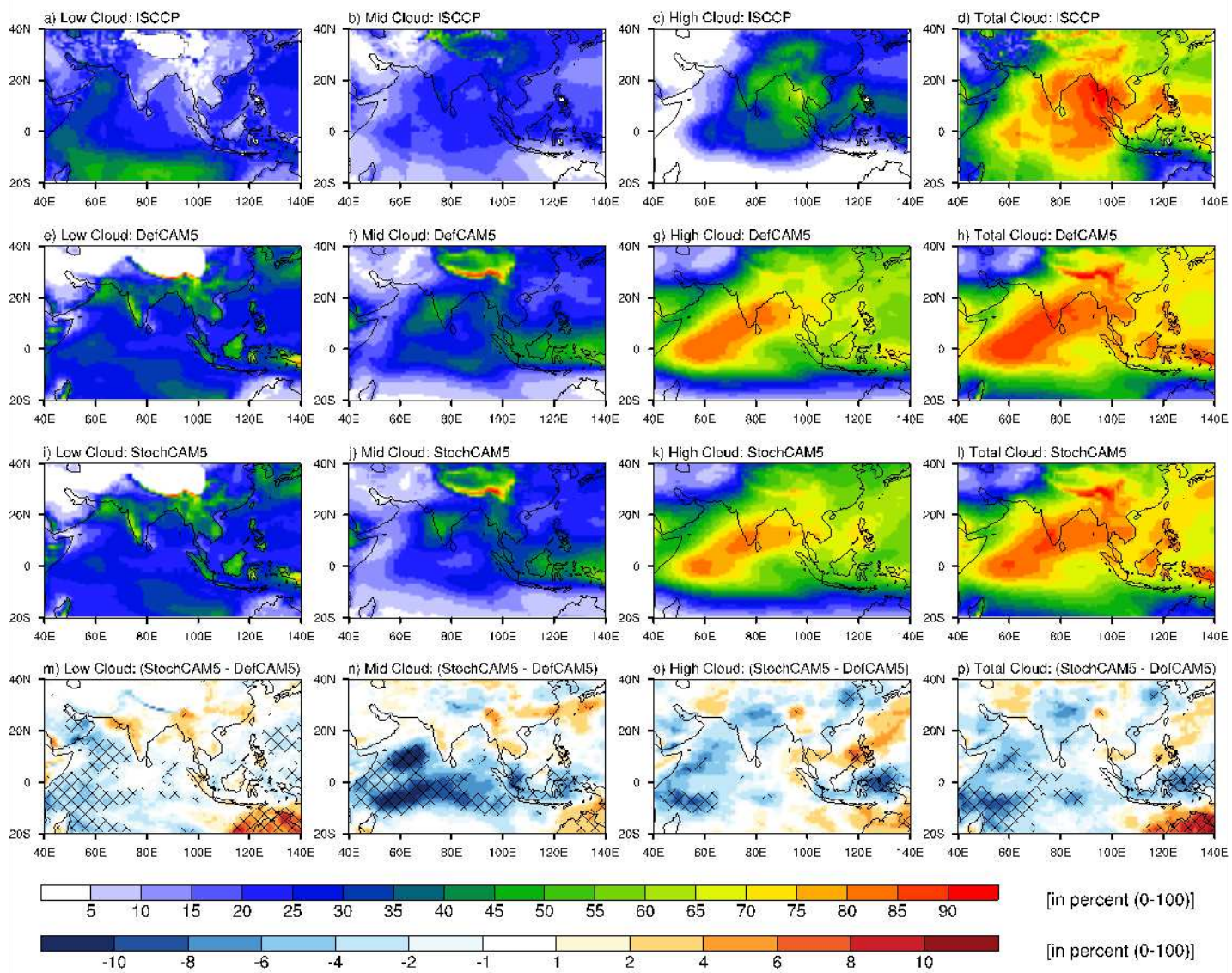

[in percent $(0-100)]$

[in percent $(0-100)]$

869 Figure 11: JJAS mean low, middle, high, and total cloud cover distribution over South Asia for

870 (a-d) ISCCP, (e-h) DefCAM5, and (i-l) StochCAM5, as well as the difference for (m-p)

871 StochCAM5 - DefCAM5. Hatching (stippling) shows the differences which are improved

872 (deteriorated) at 95\% confidence level in StochCAM5 with respect to DefCAM5. ISCCP -

873 International Satellite Cloud Climatology Project. 

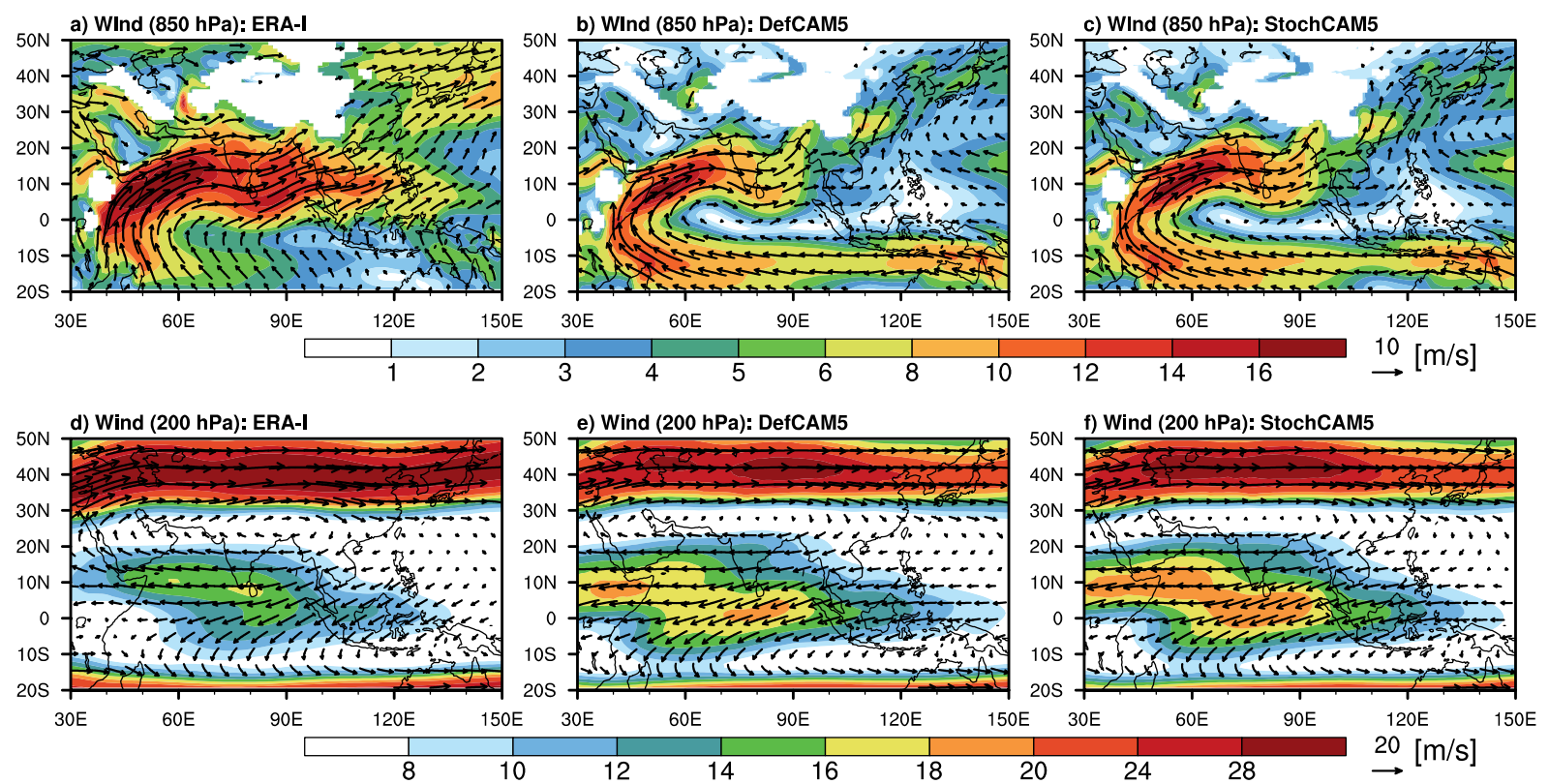

Figure 12: JJAS mean (a-c) low-level wind at $850 \mathrm{hPa}$ and (d-f) upper-level wind at $200 \mathrm{hPa}$ for

876 (a, d) ERA-I, (b, e) DefCAM5, and (c, f) StochCAM5.

877

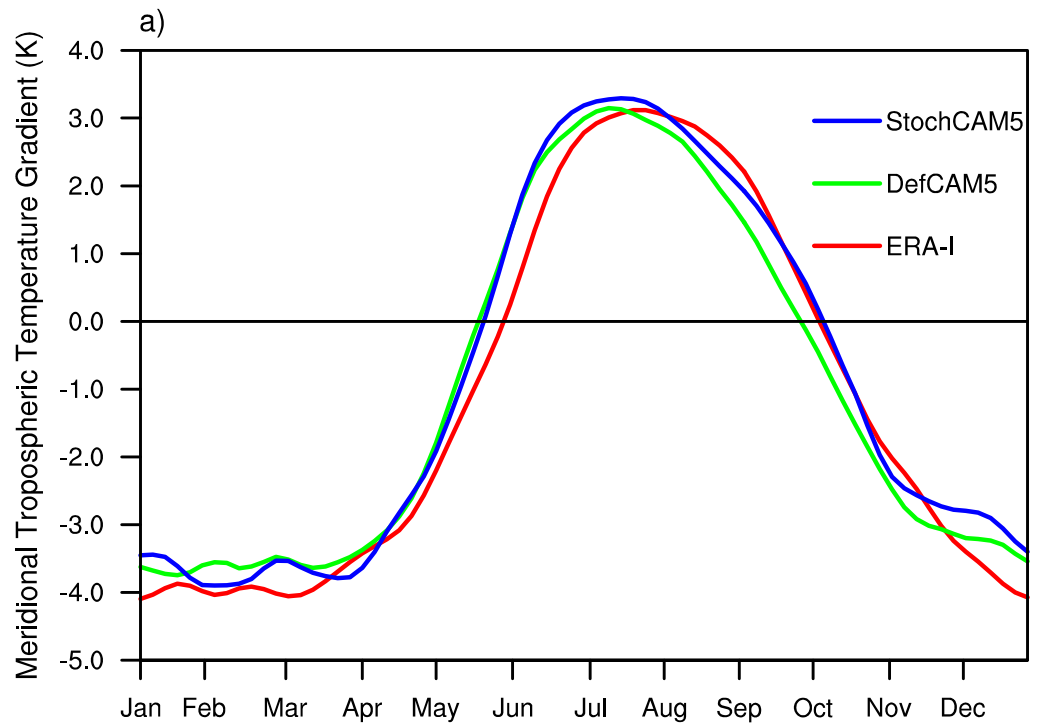

879 Figure 13: The annual cycle of meridional tropospheric temperature gradient (MTTG) for ERA-I

880 (red), DefCAM5 (green), and StochCAM5 (blue). MTTG is estimated by taking the difference of

881 vertically averaged $(600-200 \mathrm{hPa})$ temperature between the two boxes - one over $5^{\circ}-35^{\circ} \mathrm{N}$ and

$88240^{\circ}-100^{\circ} \mathrm{E}$ and other over $5^{\circ} \mathrm{N}-15^{\circ} \mathrm{S}$ and $40-100^{\circ} \mathrm{E}$. MTTG also defines the monsoon onset date 
883 when this changes the sign from negative to positive on the annual cycle and the vice-versa for the 884 monsoon withdrawal.
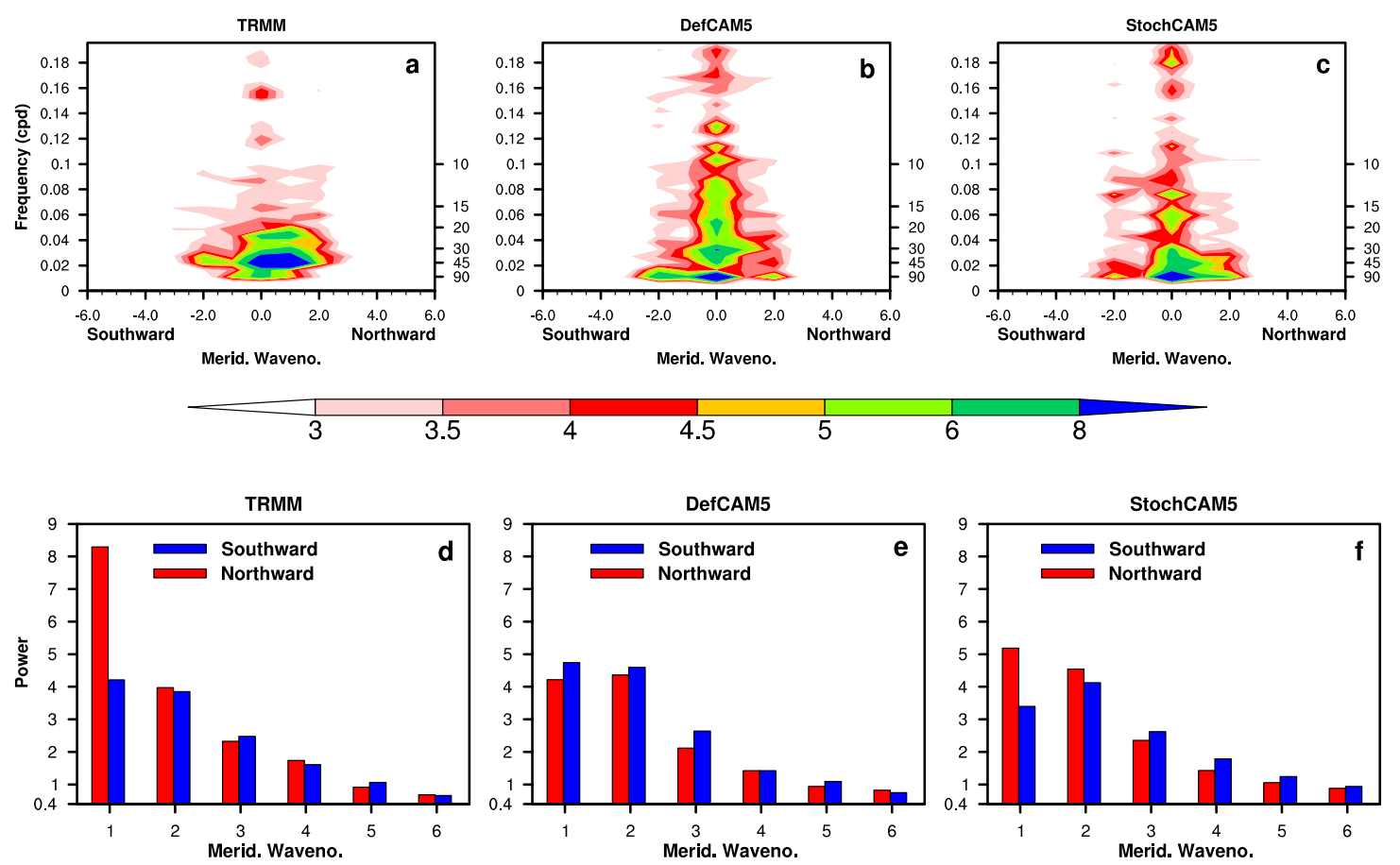

887 Figure 14: The north-south wavenumber-frequency spectra of precipitation during JJAS for (a)

888 TRMM, (b) DefCAM5, and (c) StochCAM5 over the domain of $15^{\circ} \mathrm{S}-30^{\circ} \mathrm{N}$ and $60^{\circ}-95^{\circ} \mathrm{E}$. The 889 power of precipitation spectrum separated as the northward and southward component, which is 890 calculated from the north-south wavenumber-frequency spectra of precipitation averaged over 3089190 days period for (d) TRMM, (e) DefCAM5, and (f) StochCAM5. 

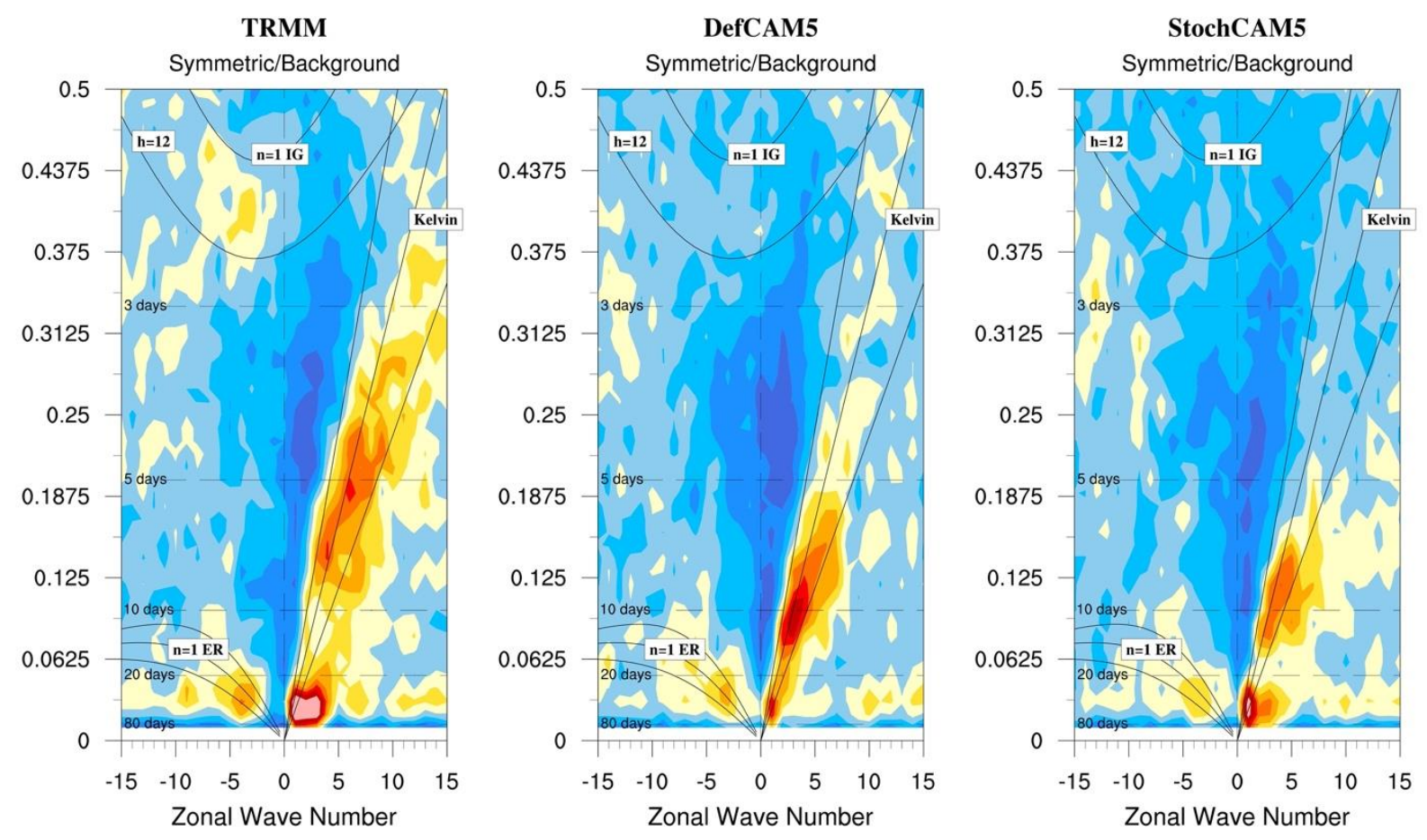

893

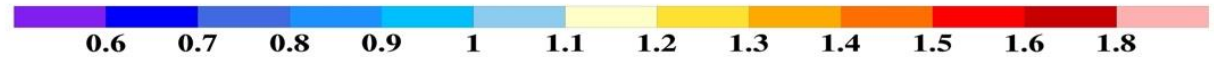

894 Figure 15: The symmetric component of Wheeler-Kiladis space-time power spectrum for (a)

895 TRMM, (b) DefCAM5, and (c) StochCAM5. It is computed from the daily time-series of total 896 precipitation in the global belt of equatorial region $\left(15^{\circ} \mathrm{N}-15^{\circ} \mathrm{S}\right)$ during JJAS. 


\section{Figures}

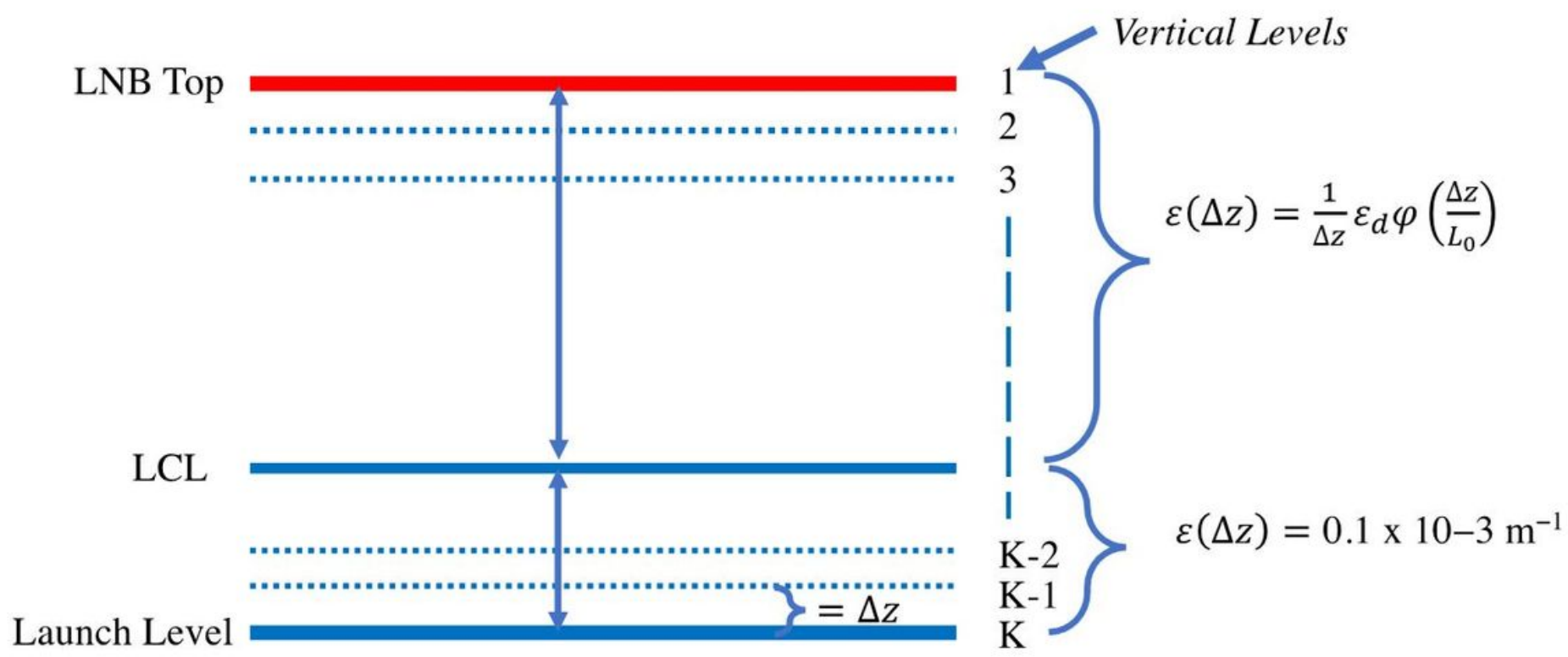

\section{Figure 1}

Structure of the stochastic entrainment rate implemented in the ZMNR deep convection scheme. Entrainment rate $(\varepsilon)$ from the parcel launch level to lifting condensation level (LCL) is kept the same as default value $\varepsilon(\Delta z)=0.1 \times 10-3 \mathrm{~m}-1$. Entrainment above $L C L$ is stochastically computed until the level of neutral buoyancy (LNB). The levels used here are the default model levels and the distance $\Delta z$ is the difference between the two model levels. 


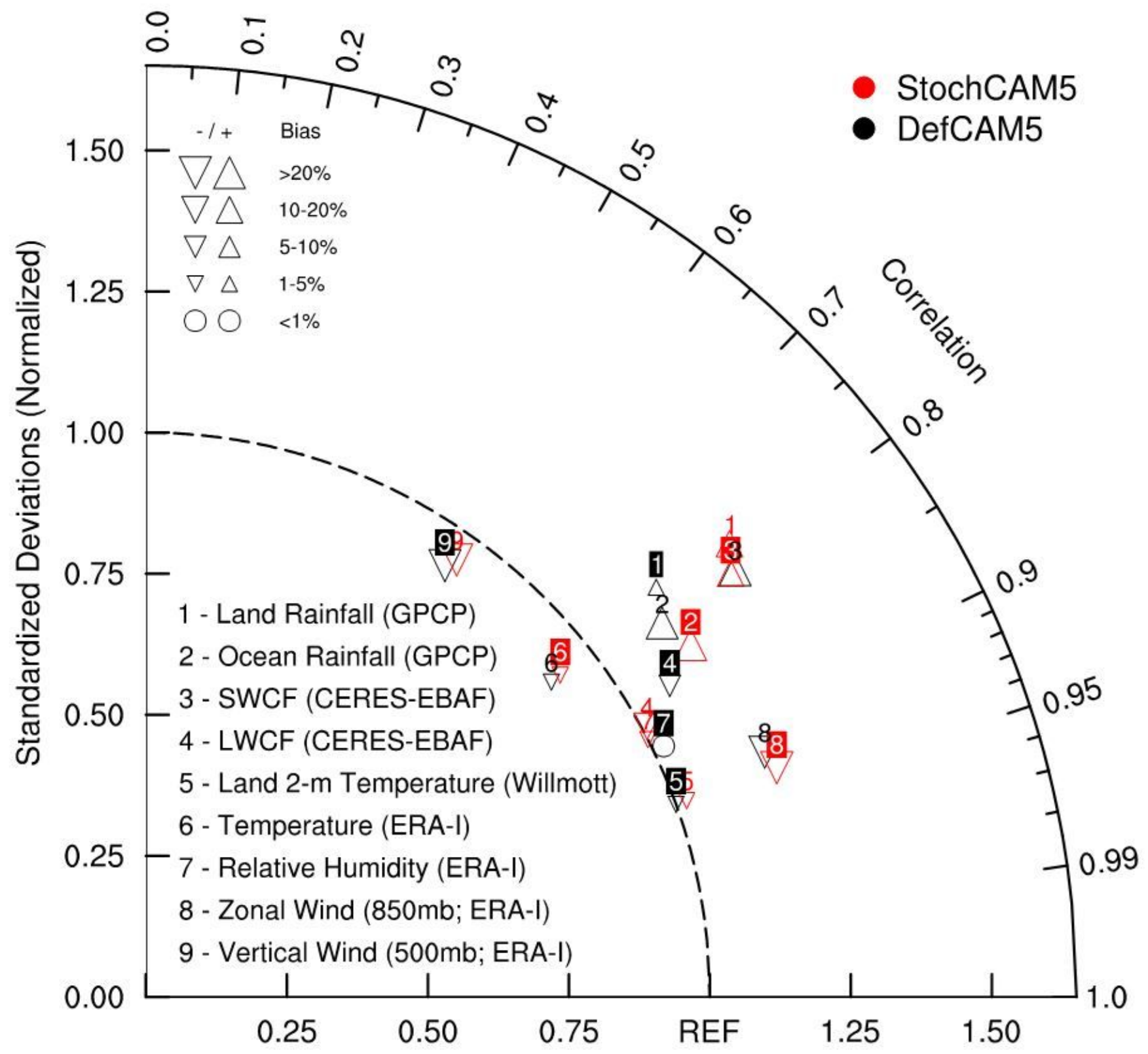

Figure 2

Taylor diagram with metrics for DefCAM5 and StochCAM5 over the tropics $\left(30^{\circ} \mathrm{S}-30^{\circ} \mathrm{N}\right)$. The specific humidity (point 6) and temperature (point 7) are the mass-weighted vertical average from 1000-100 hPa. The four metrics used here are the Pearson correlation coefficient (represented by the cosine of the angle from the horizontal axis), the centered root mean square error (represented by the distance from the point on the horizontal axis defined as the reference point or REF), the normalized standard deviation (represented by the radial distance from the origin), and the percentage error (represented by the size of markers). 
a) Precipitation (Land)

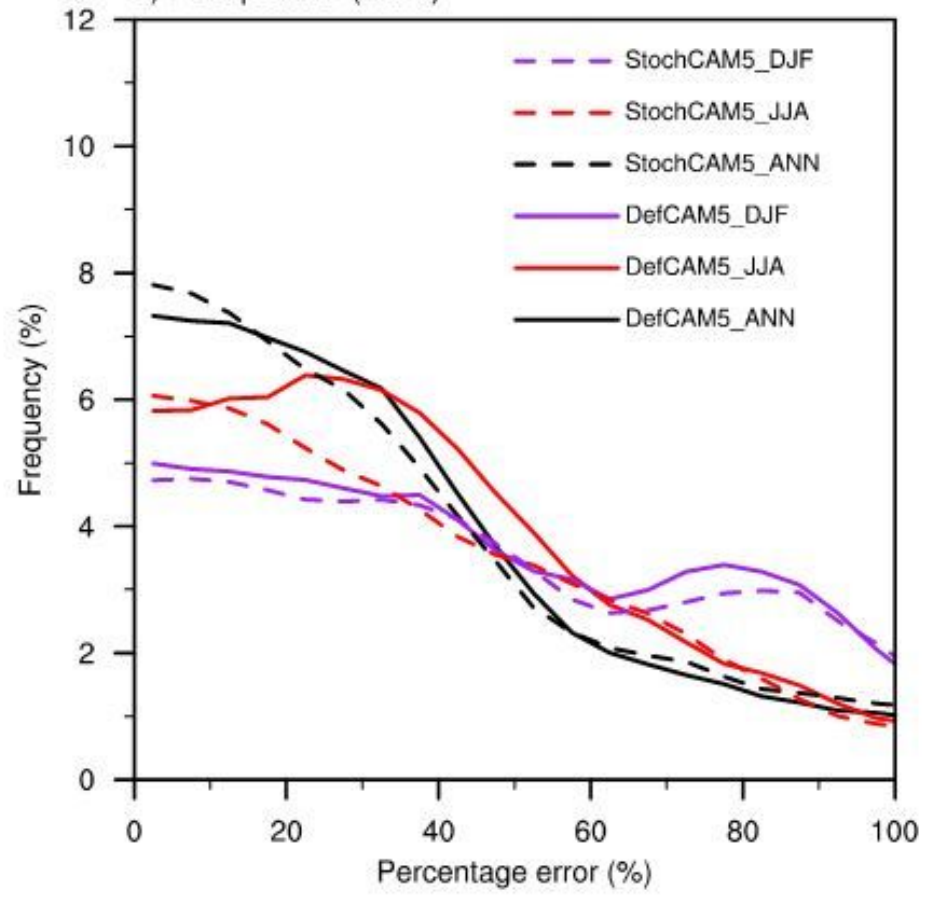

c) Precipitation (Ocean)

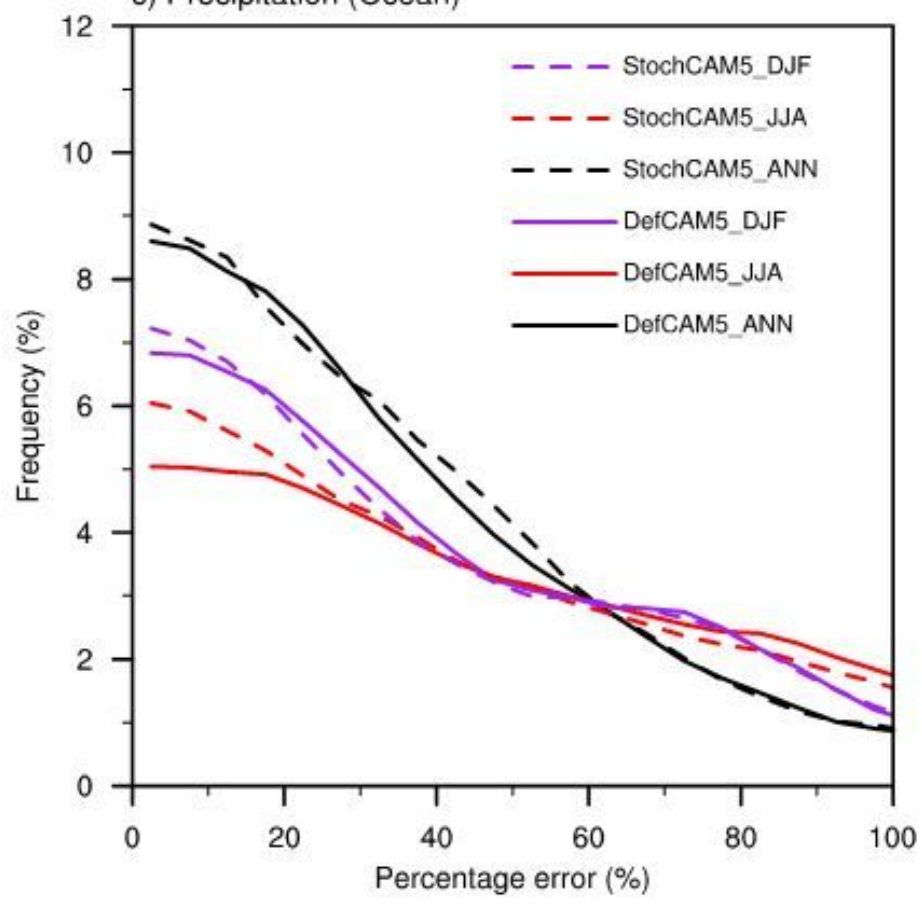

b) StochCAM5 - DefCAM5 (Land)

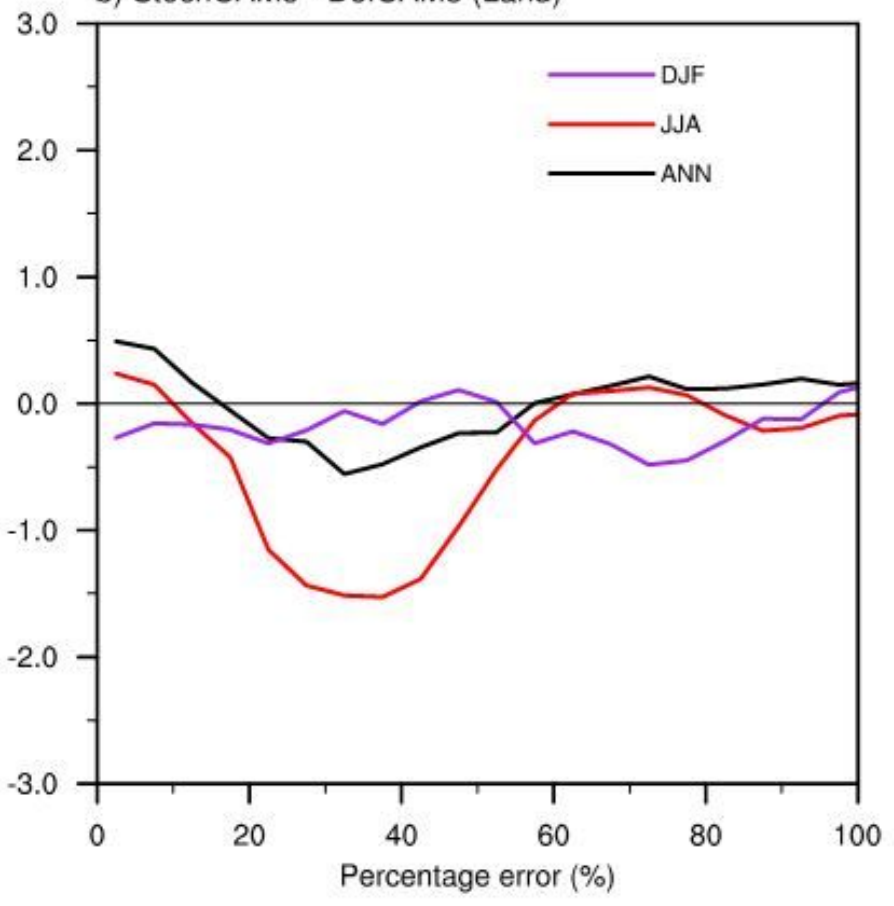

d) StochCAM5 - DefCAM5 (Ocean)

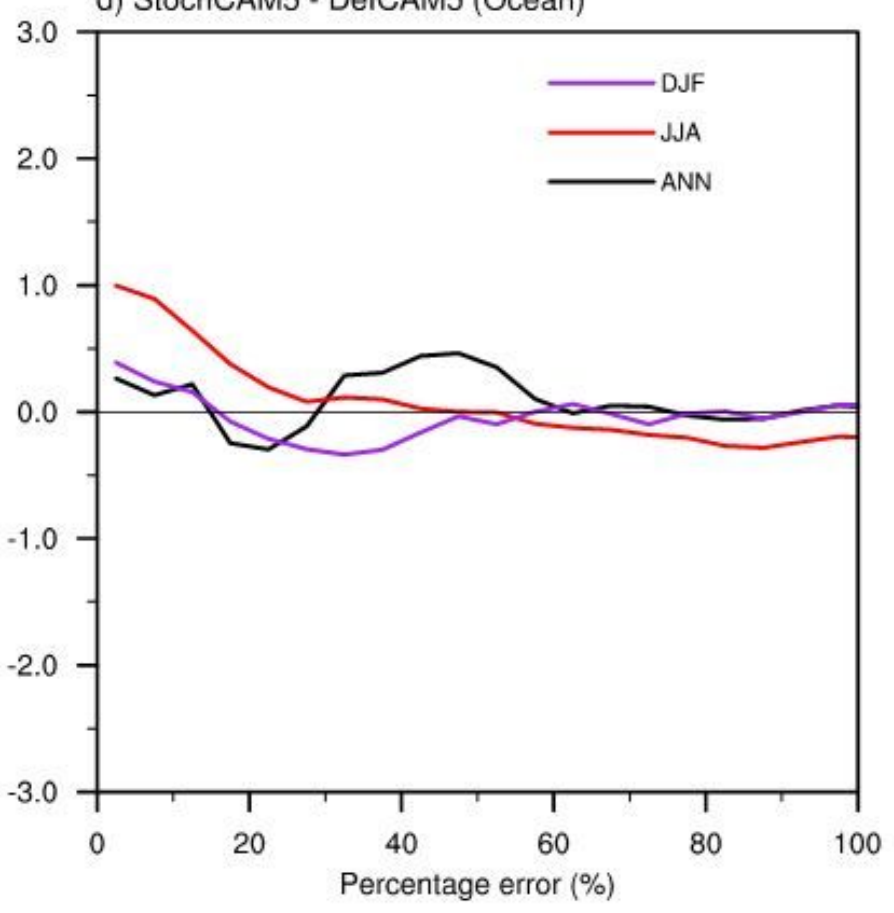

\section{Figure 3}

The frequency distribution of percentage bias for annual and seasonal (JJA and DJF) mean precipitation over the tropical land and ocean $\left(30^{\circ} \mathrm{S}-30^{\circ} \mathrm{N}\right)$ from DefCAM5 and StochCAM5, as well as their differences. The $5 \%$ bin interval is used in computing the frequency of percentage bias. 

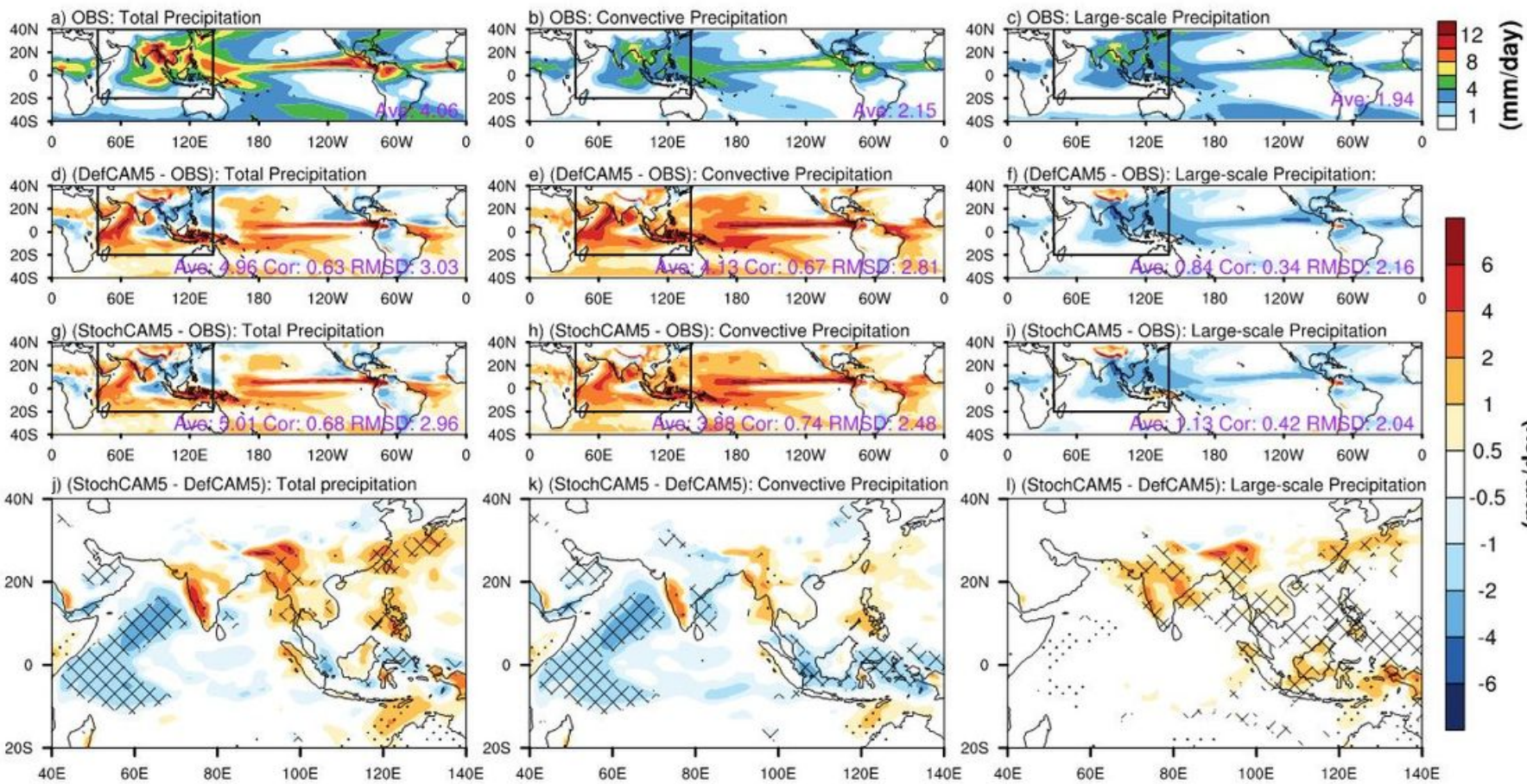

츨

\section{Figure 4}

Spatial variation of JJAS mean precipitation. a-c shows the JJAS mean (a) total precipitation, (b) convective precipitation and c) large-scale precipitation from GPCP observations over the tropics. $d$ - $f$ and $\mathrm{g}-\mathrm{i}$ shows the difference in total, convective, and large-scale precipitation for DefCAM5 and StochCAM5 with respect to observations, respectively over the tropics. $\mathrm{j}-\mathrm{I}$ shows the difference in total, convective, and large-scale precipitation for StochCAM5 with respect to DefCAM5 over South Asia (the zoomed region in black rectangle). The average value (Ave.), correlation (Corr.), and the root mean square difference (RMSD) for precipitation over South Asia are also shown at the bottom of a-i. Hatching (stippling) shows the differences which are improved (deteriorated) at 95\% confidence level (two-tailed student t-test) in StochCAM5 with respect to DefCAM5. Note: The designations employed and the presentation of the material on this map do not imply the expression of any opinion whatsoever on the part of Research Square concerning the legal status of any country, territory, city or area or of its authorities, or concerning the delimitation of its frontiers or boundaries. This map has been provided by the authors. 
a) Total Precipitation Annual Cycle

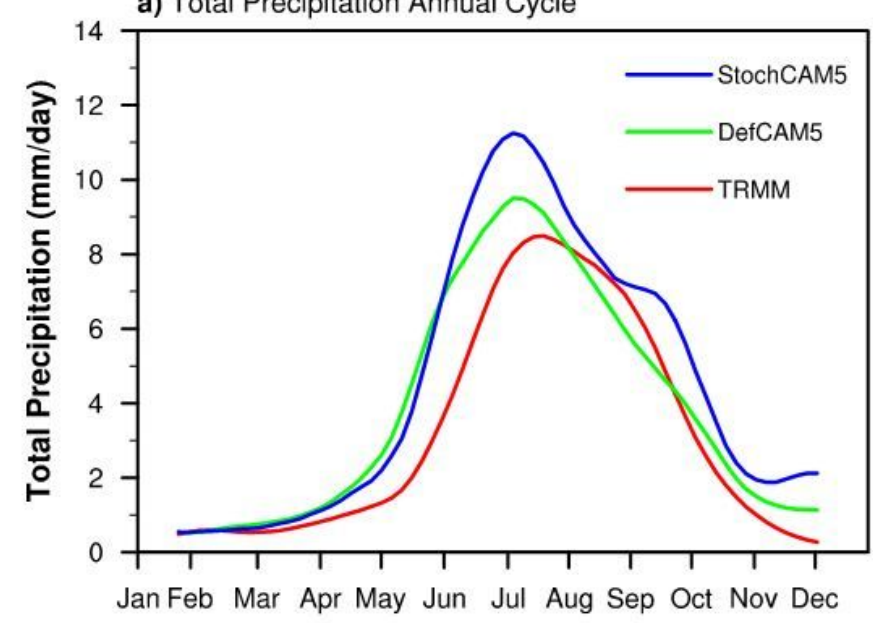

b) Frequency Distribution of Total precipitation

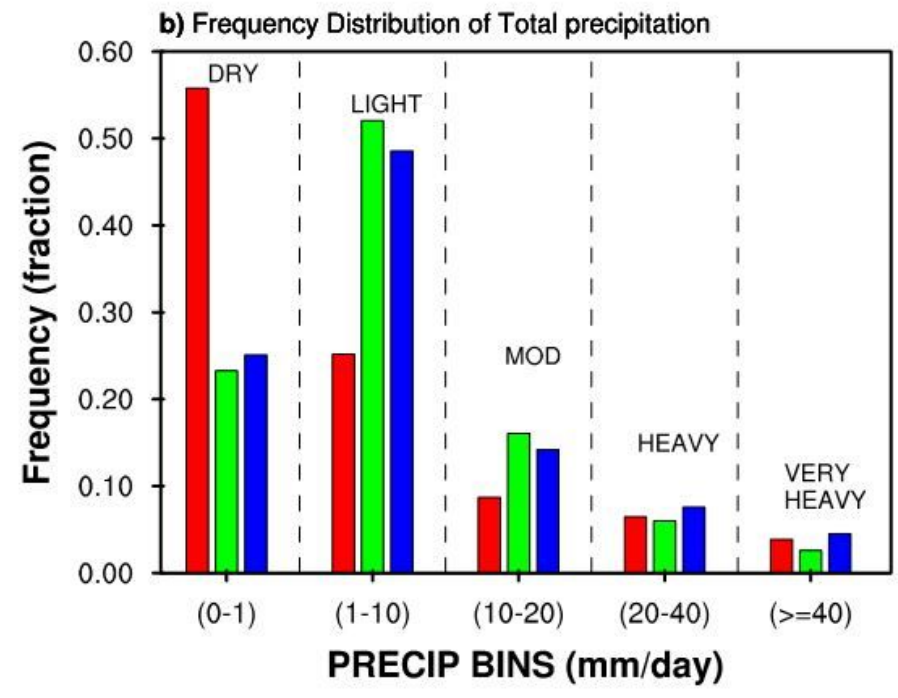

c) Cumulative Distribution of Total precipitation

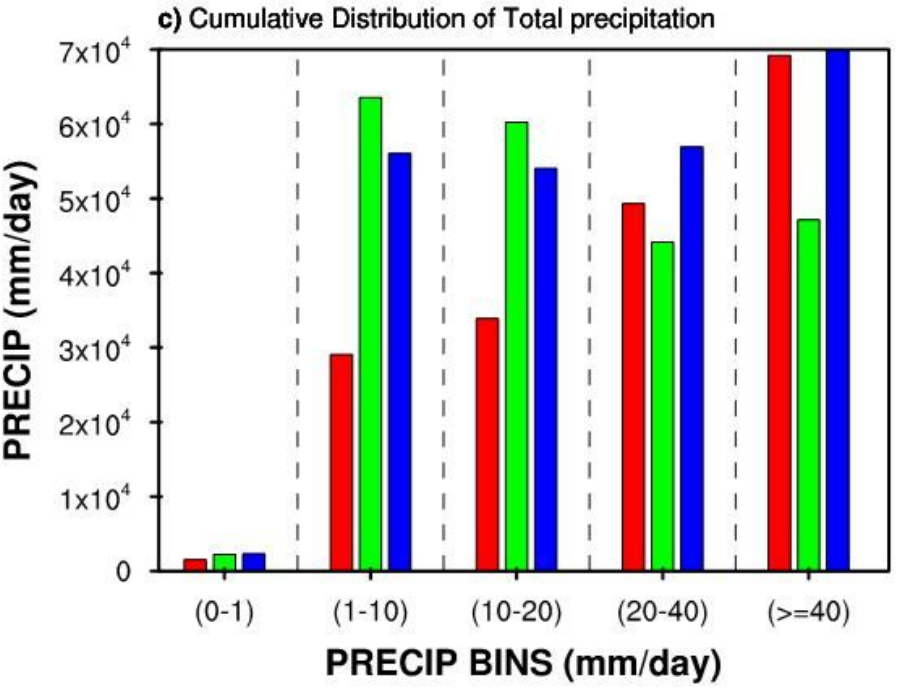

Figure 5

(a) annual total precipitation cycle, (b) frequency distribution of daily precipitation rate over the Indian land during JJAS, and c) amount of precipitation falling in each bin of precipitation rate over the Indian land during JJAS. 

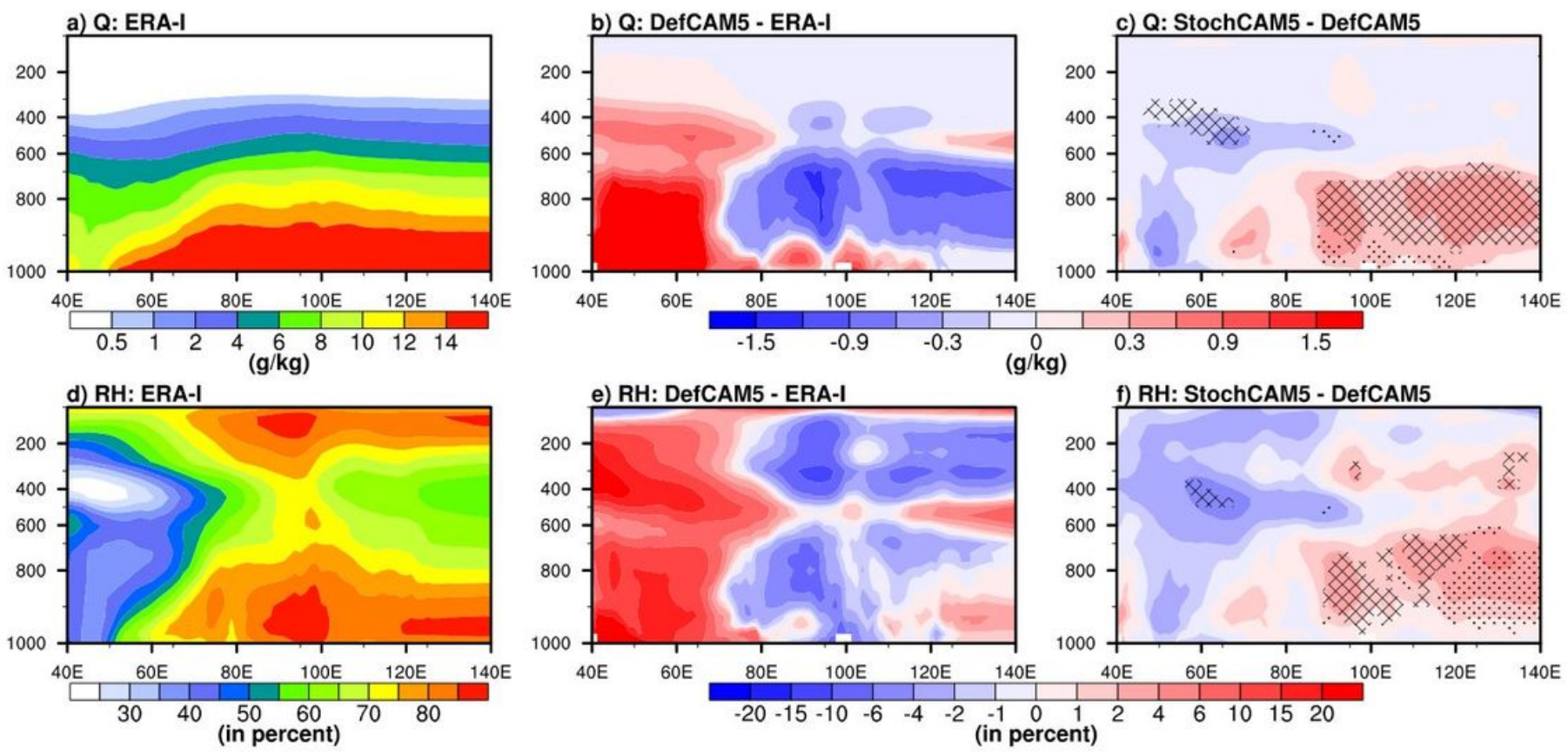

Figure 6

The JJAS meridional mean cross sections of (a-c) specific humidity and (d-f) relative humidity in belt of Indian latitudes $\left(0^{\circ}-30^{\circ} \mathrm{N}\right)$ for $(\mathrm{a}, \mathrm{d})$ ERA-I, $(\mathrm{b}, \mathrm{e})$ DefCAM5 -ERA-I, and $(\mathrm{c}, \mathrm{f})$ StochCAM5 -DefCAM5. Hatching (stippling) shows the differences which are improved (deteriorated) at $95 \%$ confidence level in StochCAM5 with respect to DefCAM5. Q - specific humidity; RH - relative humidity.
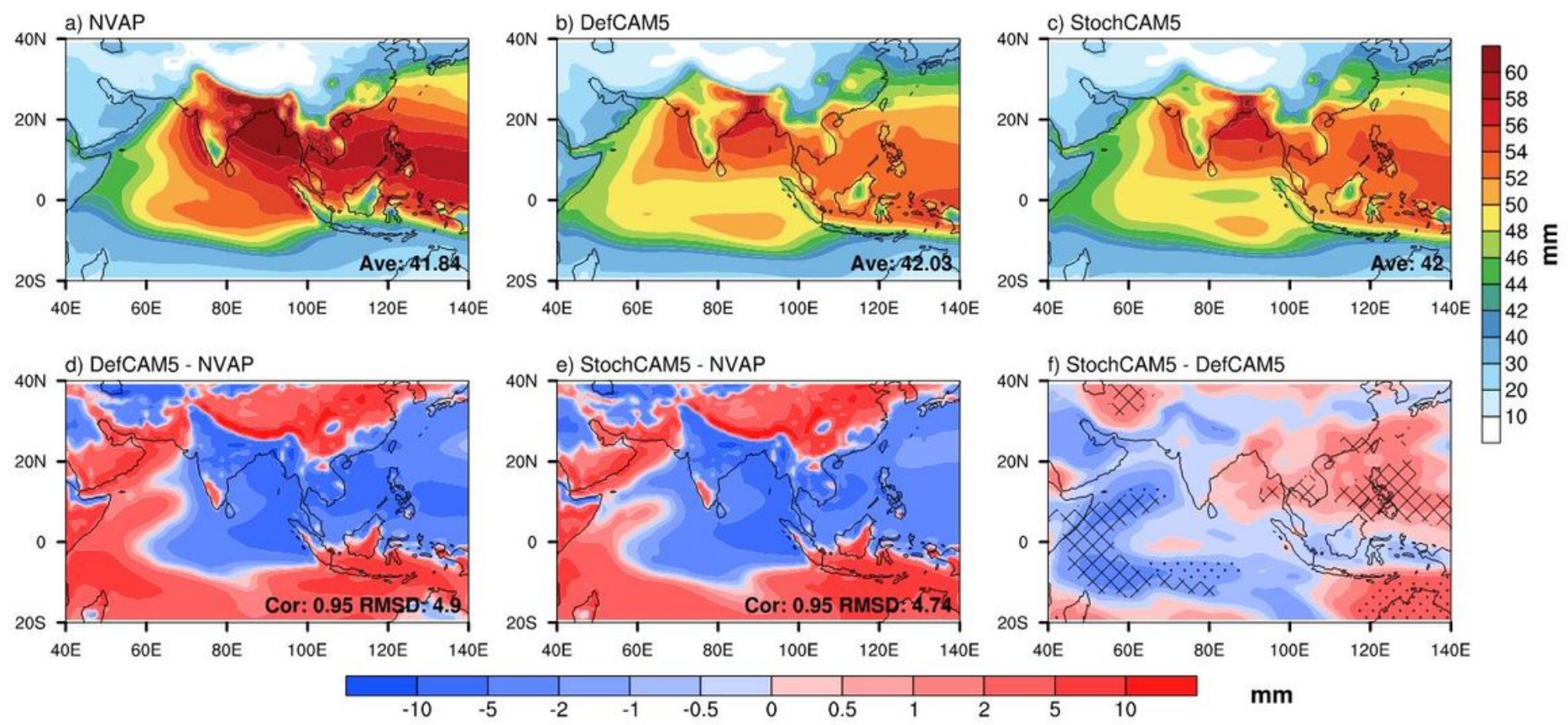

Figure 7 
JJAS mean total column water vapor over South Asia for (a) NVAP, (b) DefCAM5, and (c) StochCAM5 as well as their differences for (d) DefCAM5 - NVAP, (e) StochCAM5 - NVAP, and (f) StochCAM5 - DefCAM5. Hatching (stippling) shows the differences which are improved (deteriorated) at 95\% confidence level in StochCAM5 with respect to DefCAM5. NVAP - National Aeronautics and Space Administration (NASA) Water Vapor Project. Note: The designations employed and the presentation of the material on this map do not imply the expression of any opinion whatsoever on the part of Research Square concerning the legal status of any country, territory, city or area or of its authorities, or concerning the delimitation of its frontiers or boundaries. This map has been provided by the authors.
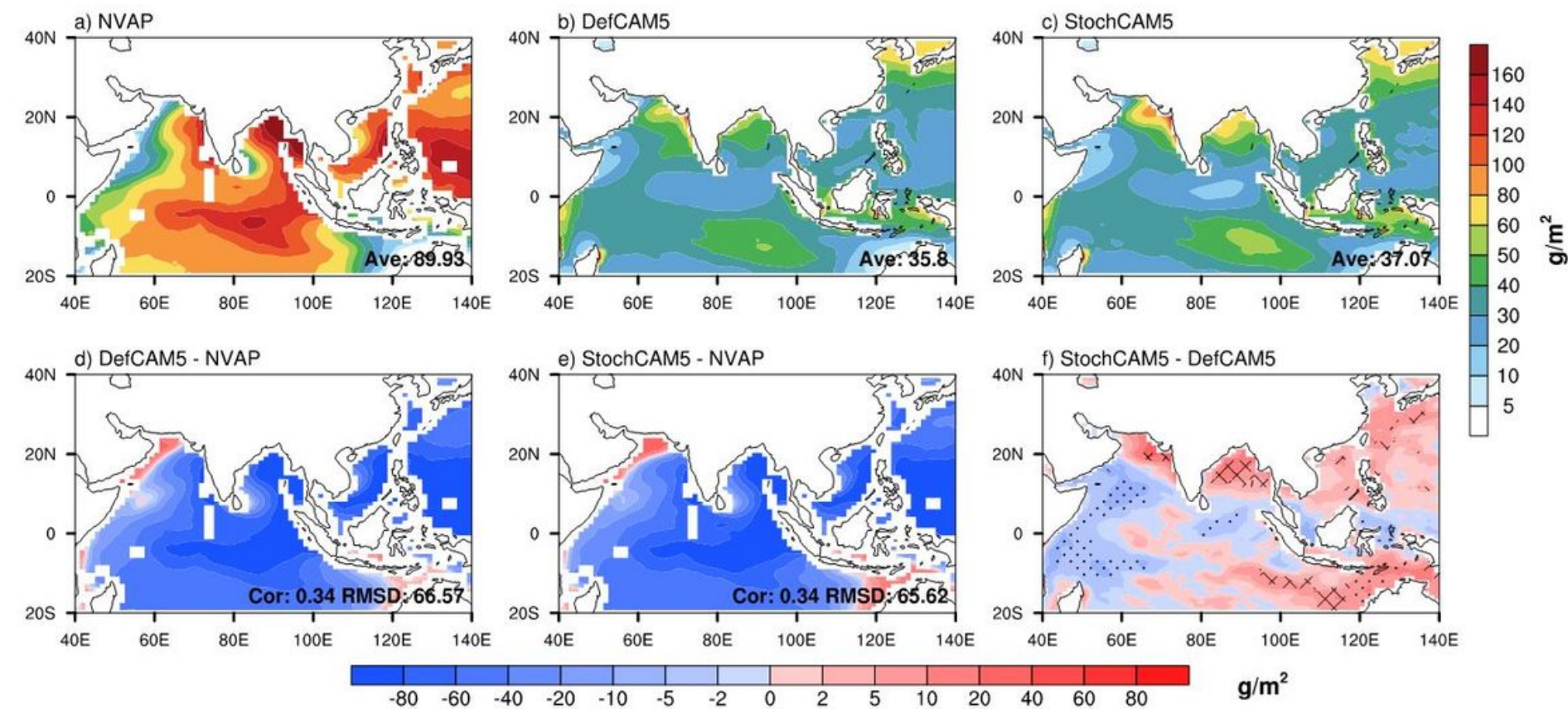

\section{Figure 8}

JJAS mean total liquid water path (LWP) over South Asia for (a) NVAP, (b) DefCAM5, and (c) StochCAM5 as well as their differences for (d) DefCAM5 - NVAP, (e) StochCAM5 - NVAP, and (f) StochCAM5 DefCAM5. Hatching (stippling) shows the differences which are improved (deteriorated) at $95 \%$ confidence level in StochCAM5 with respect to DefCAM5. Note: The designations employed and the presentation of the material on this map do not imply the expression of any opinion whatsoever on the part of Research Square concerning the legal status of any country, territory, city or area or of its authorities, or concerning the delimitation of its frontiers or boundaries. This map has been provided by the authors. 


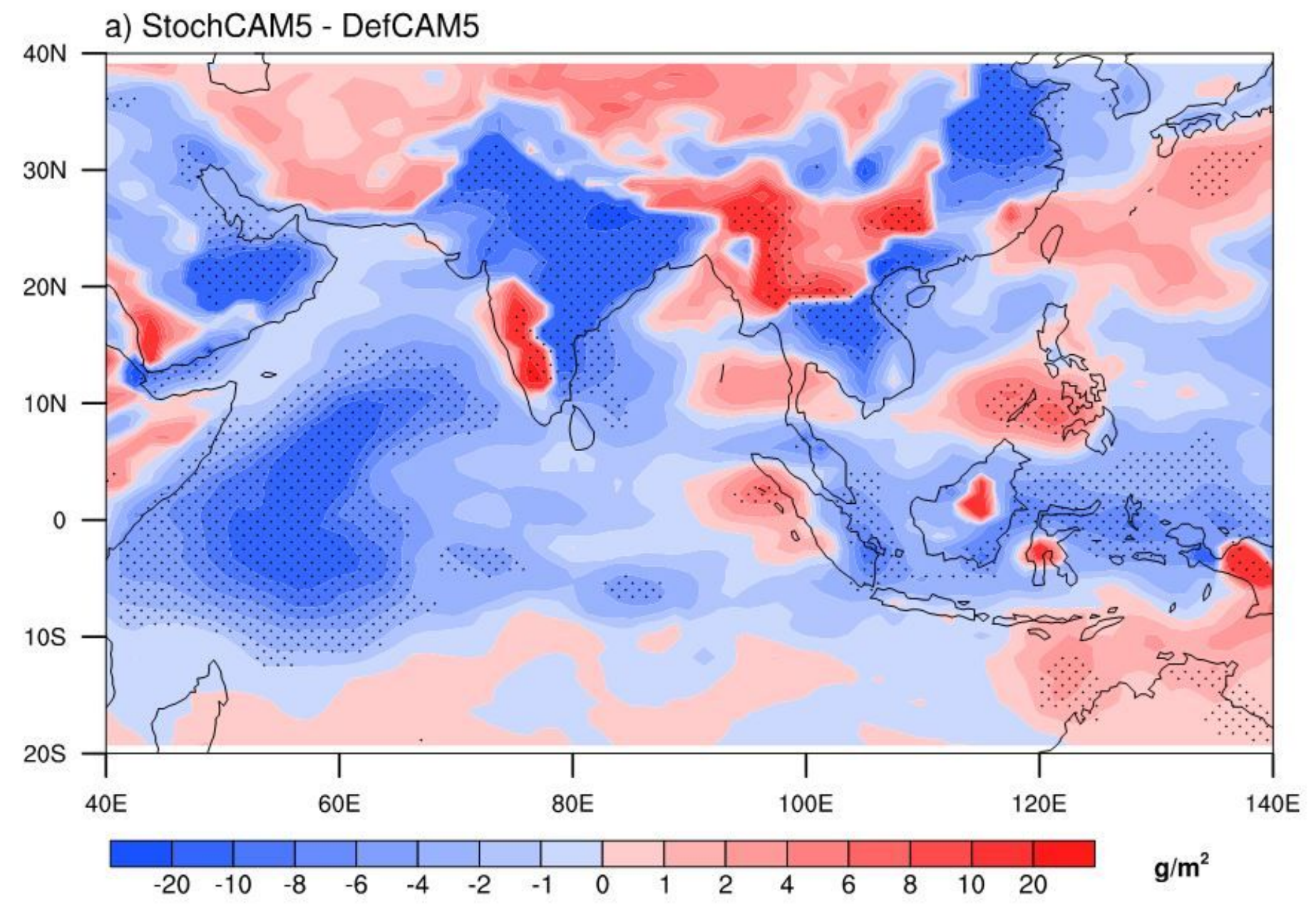

Figure 9

JJAS mean difference of ice water path (IWP) over South Asia between StochCAM5 and DefCAM5. The stippled regions show the differences which are significant at $95 \%$ confidence level. Note: The designations employed and the presentation of the material on this map do not imply the expression of any opinion whatsoever on the part of Research Square concerning the legal status of any country, territory, city or area or of its authorities, or concerning the delimitation of its frontiers or boundaries. This map has been provided by the authors. 

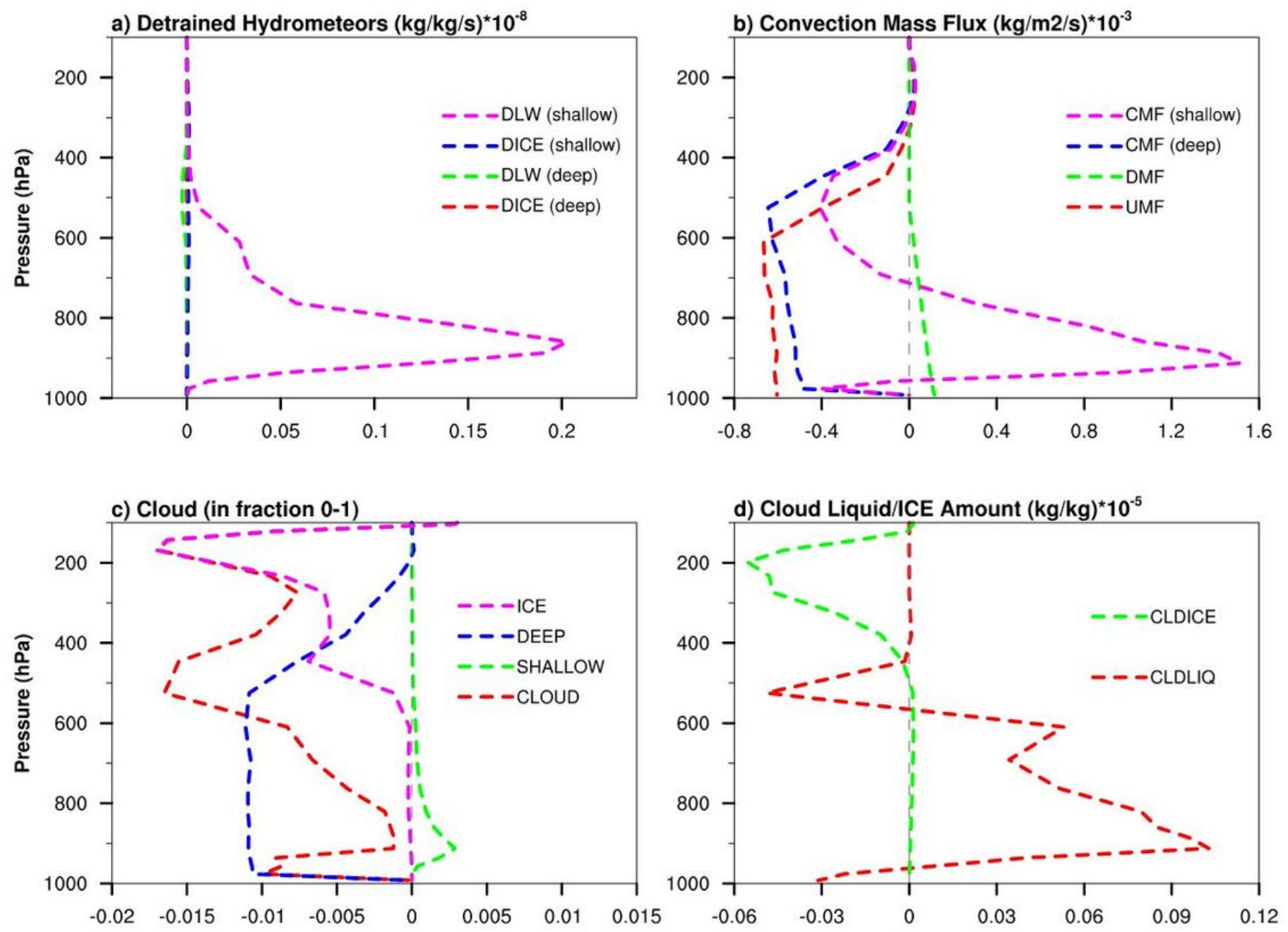

Figure 10

JJAS mean difference of (a) detrained liquid water (DLW) and detrained ice (DICE) from deep and shallow convection, (b) updraft mass flux (UMF), downdraft mass flux (DMF), convective mass flux (CMF) for shallow and deep convection, (c) cloud cover distribution of ice, deep, shallow, and total cloud, and (d) cloud liquid and cloud ice amount over South Asia. 

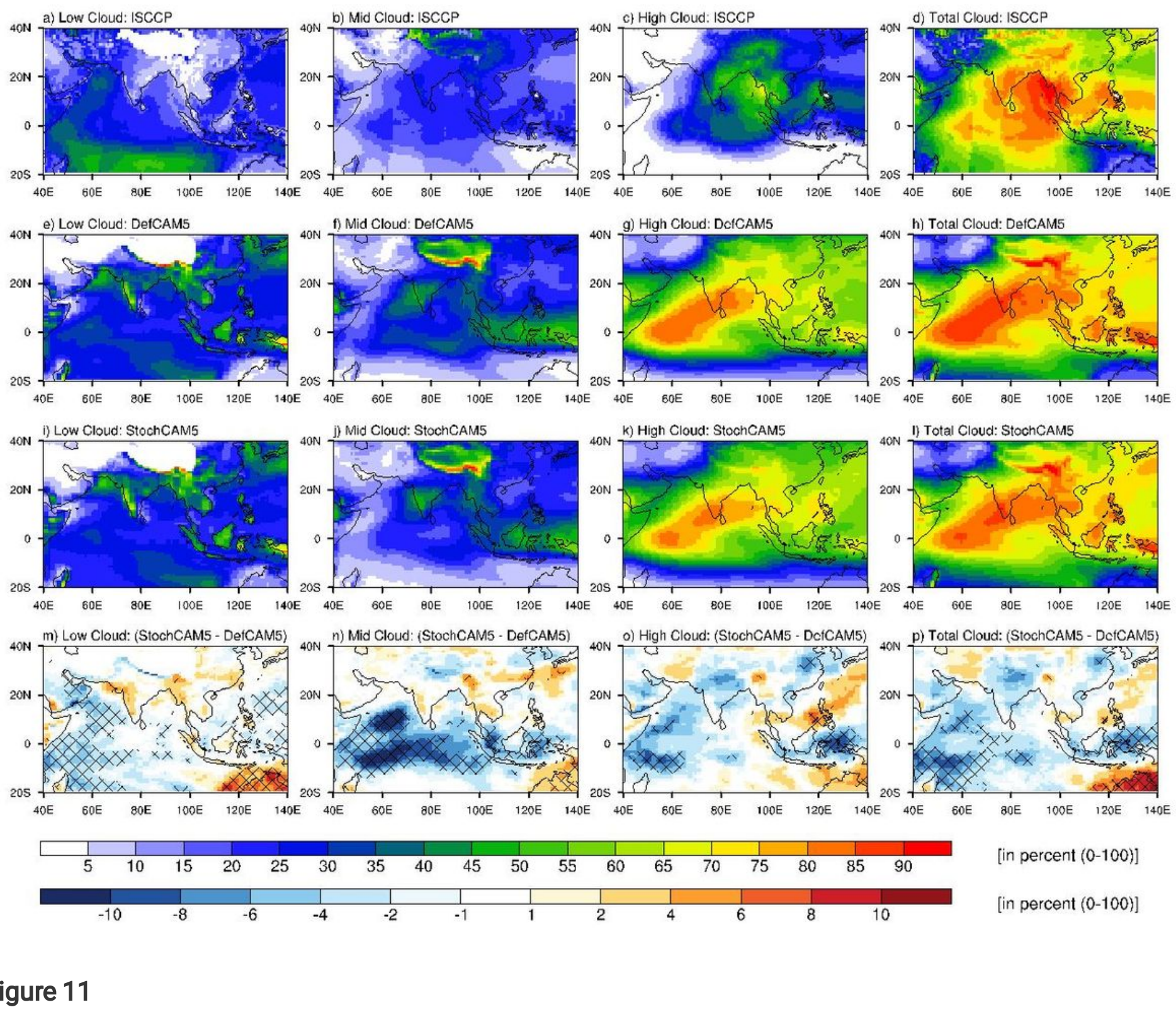

\section{Figure 11}

JJAS mean low, middle, high, and total cloud cover distribution over South Asia for (a-d) ISCCP, (e-h) DefCAM5, and (i-1) StochCAM5, as well as the difference for (m-p) StochCAM5 - DefCAM5. Hatching (stippling) shows the differences which are improved (deteriorated) at 95\% confidence level in StochCAM5 with respect to DefCAM5. ISCCP - International Satellite Cloud Climatology Project. Note: The designations employed and the presentation of the material on this map do not imply the expression of any opinion whatsoever on the part of Research Square concerning the legal status of any country, territory, city or area or of its authorities, or concerning the delimitation of its frontiers or boundaries. This map has been provided by the authors. 

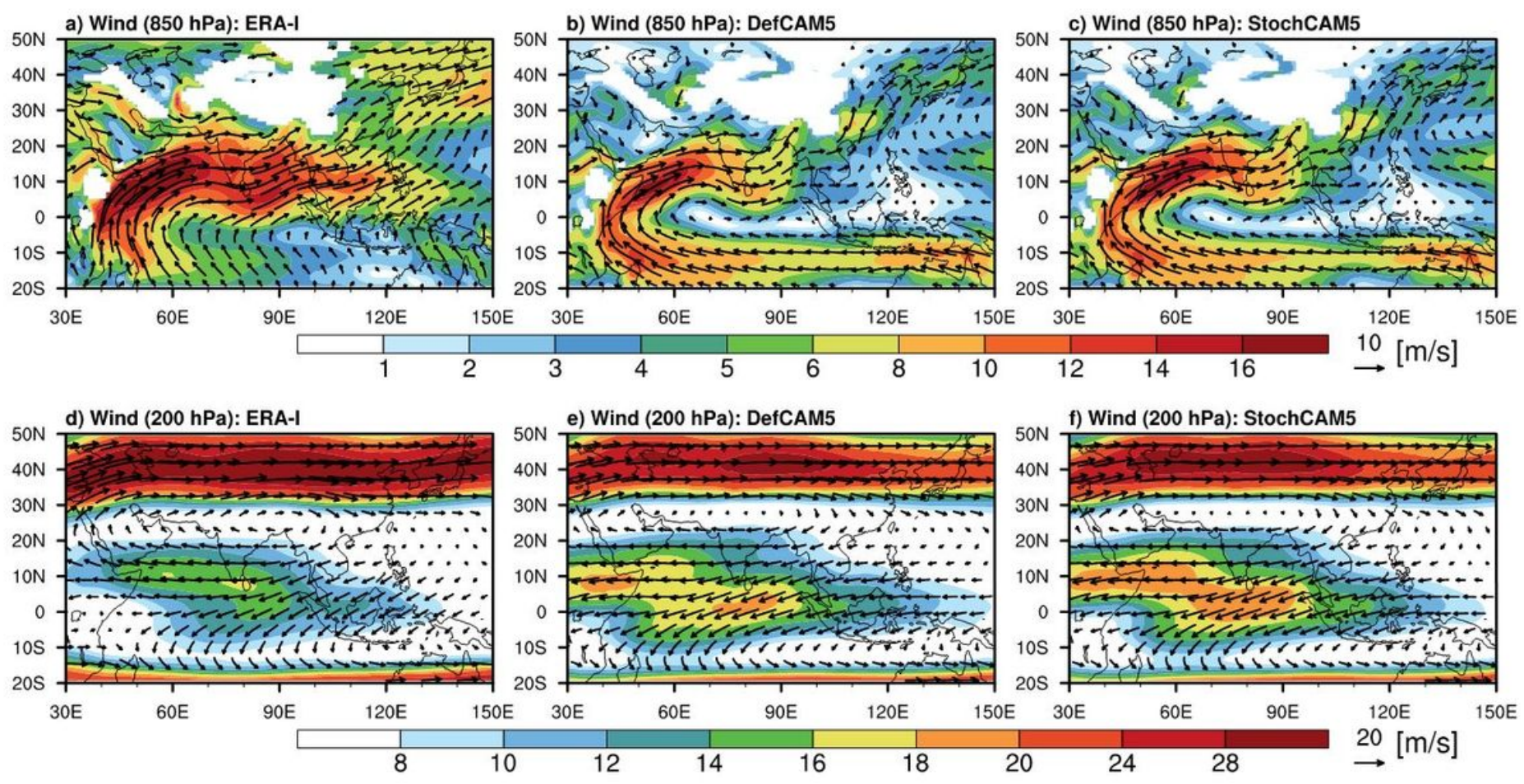

Figure 12

JJAS mean (a-c) low-level wind at $850 \mathrm{hPa}$ and (d-f) upper-level wind at $200 \mathrm{hPa}$ for (a, d) ERA-l, (b, e) DefCAM5, and $(c, f)$ StochCAM5. Note: The designations employed and the presentation of the material on this map do not imply the expression of any opinion whatsoever on the part of Research Square concerning the legal status of any country, territory, city or area or of its authorities, or concerning the delimitation of its frontiers or boundaries. This map has been provided by the authors. 


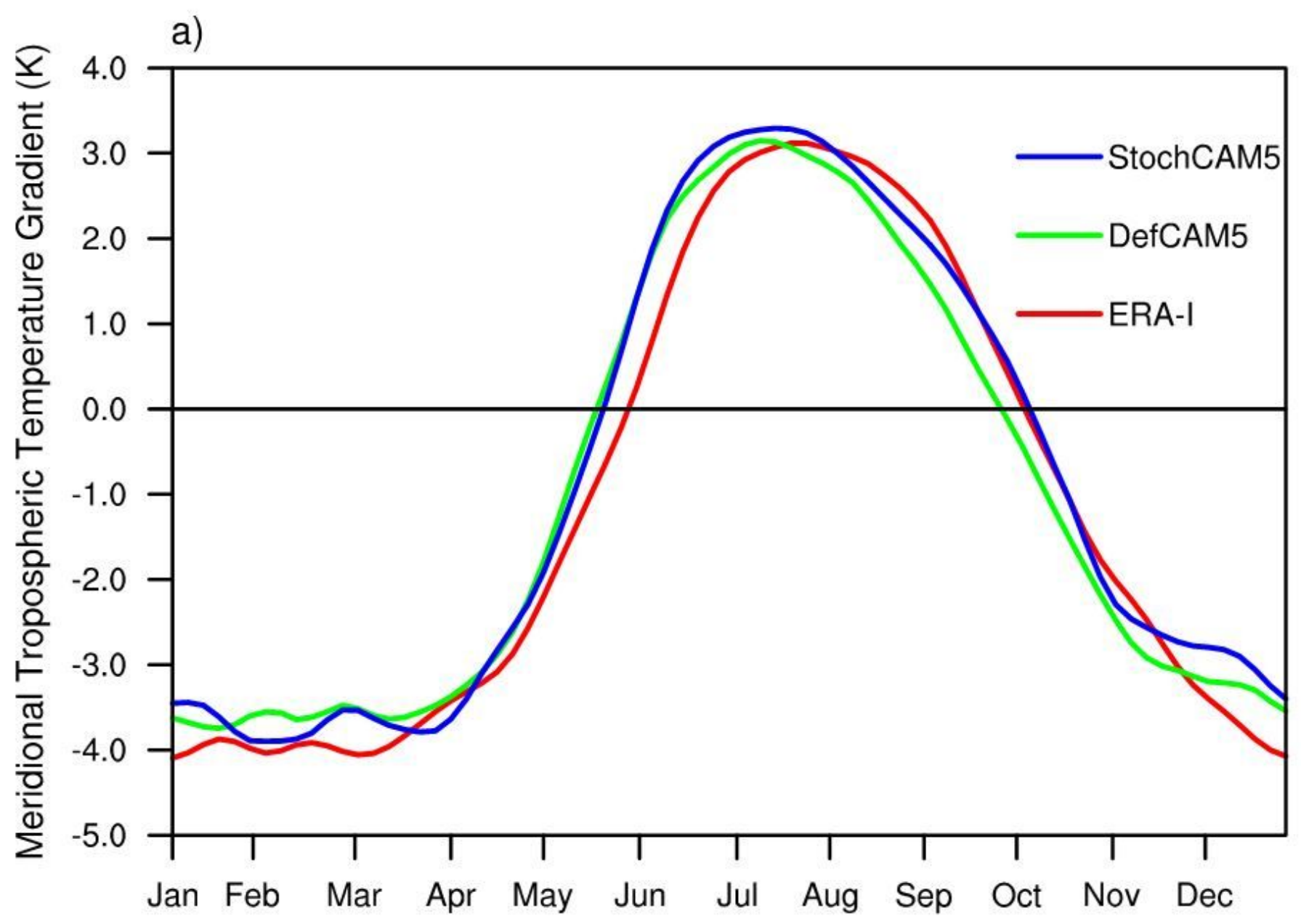

Figure 13

The annual cycle of meridional tropospheric temperature gradient (MTTG) for ERA-I (red), DefCAM5 (green), and StochCAM5 (blue). MTTG is estimated by taking the difference of vertically averaged (600$200 \mathrm{hPa}$ ) temperature between the two boxes - one over $5^{\circ}-35^{\circ} \mathrm{N}$ and $40^{\circ}-100^{\circ} \mathrm{E}$ and other over $5^{\circ} \mathrm{N}-15^{\circ} \mathrm{S}$ and $40-100^{\circ} \mathrm{E}$. MTTG also defines the monsoon onset date when this changes the sign from negative to positive on the annual cycle and the vice-versa for the monsoon withdrawal. 

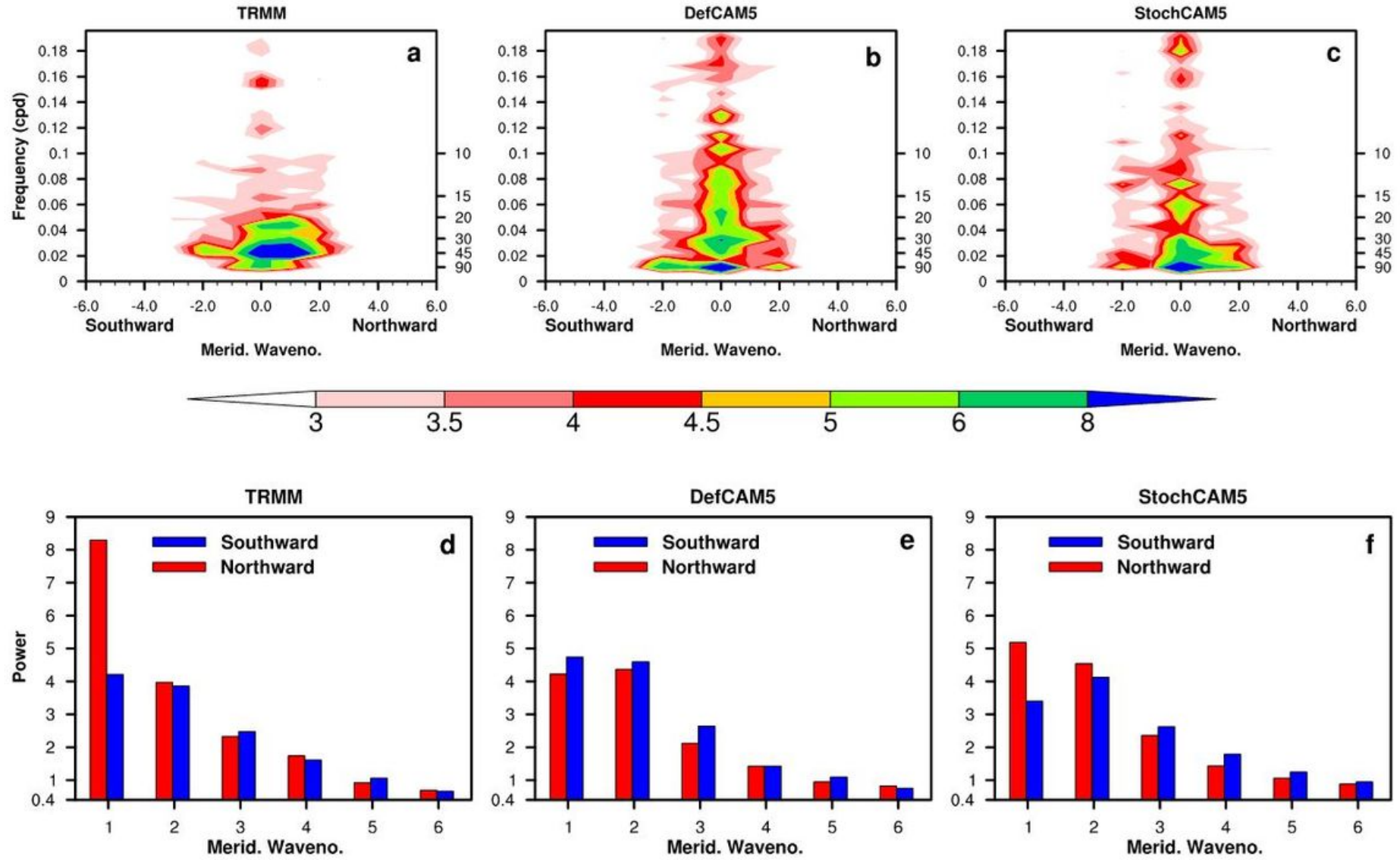

Figure 14

The north-south wavenumber-frequency spectra of precipitation during JJAS for (a) TRMM, (b) DefCAM5, and (c) StochCAM5 over the domain of $15^{\circ} \mathrm{S}-30^{\circ} \mathrm{N}$ and $60^{\circ}-95^{\circ} \mathrm{E}$. The power of precipitation spectrum separated as the northward and southward component, which is calculated from the north-south wavenumber-frequency spectra of precipitation averaged over 30-90 days period for (d) TRMM, (e) DefCAM5, and (f) StochCAM5. 

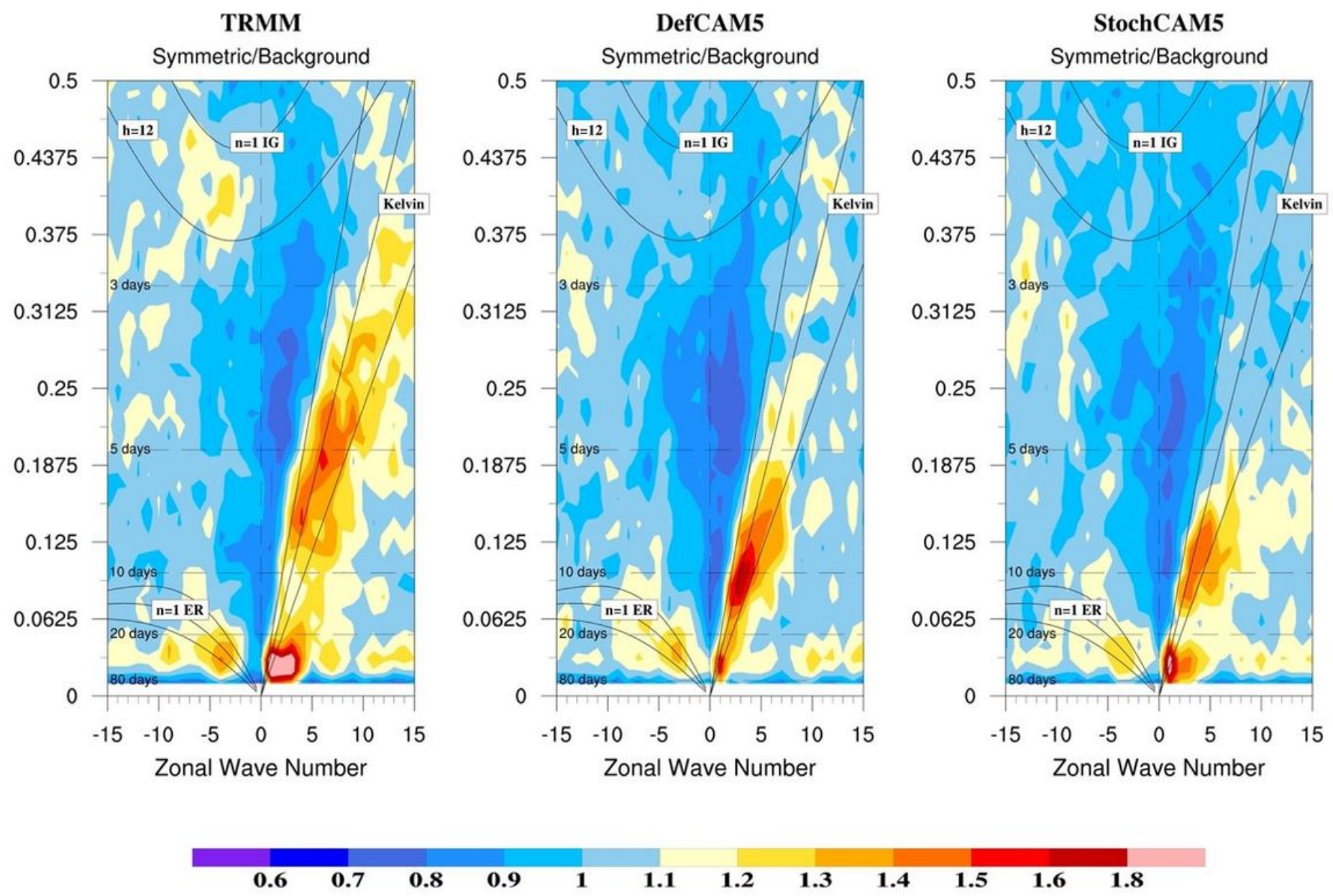

\section{Figure 15}

The symmetric component of Wheeler-Kiladis space-time power spectrum for (a) TRMM, (b) DefCAM5, and (c) StochCAM5. It is computed from the daily time-series of total precipitation in the global belt of equatorial region $\left(15^{\circ} \mathrm{N}-15^{\circ} \mathrm{S}\right)$ during JJAS.

\section{Supplementary Files}

This is a list of supplementary files associated with this preprint. Click to download.

- CLDYSupplementaryStochEntrainment.docx 